\title{
Triclosan: An Update on Biochemical and Molecular Mechanisms
}

\author{
Mohammad A. Alfhili ${ }^{1,2}$ and Myon-Hee Lee $\mathbb{D}^{1}$ \\ ${ }^{1}$ Department of Medicine (Division of Hematology/Oncology), Brody School of Medicine, East Carolina University, Greenville, \\ NC 27834, USA \\ ${ }^{2}$ Department of Clinical Laboratory Sciences, College of Applied Medical Sciences, King Saud University, Riyadh 11433, Saudi Arabia
}

Correspondence should be addressed to Myon-Hee Lee; leemy@ecu.edu

Received 30 November 2018; Revised 28 February 2019; Accepted 1 April 2019; Published 2 May 2019

Academic Editor: Demetrios Kouretas

Copyright (c) 2019 Mohammad A. Alfhili and Myon-Hee Lee. This is an open access article distributed under the Creative Commons Attribution License, which permits unrestricted use, distribution, and reproduction in any medium, provided the original work is properly cited.

\begin{abstract}
Triclosan (TCS) is a synthetic, chlorinated phenolic antimicrobial agent commonly used in commercial and healthcare products. Items made with TCS include soaps, deodorants, shampoos, cosmetics, textiles, plastics, surgical sutures, and prosthetics. A wealth of information obtained from in vitro and in vivo studies has demonstrated the therapeutic effects of TCS, particularly against inflammatory skin conditions. Nevertheless, extensive investigations on the molecular aspects of TCS action have identified numerous adversaries associated with the disinfectant including oxidative injury and influence of physiological lifespan and longevity. This review presents a summary of the biochemical alterations pertaining to TCS exposure, with special emphasis on the diverse molecular pathways responsive to TCS that have been elucidated during the present decade.
\end{abstract}

\section{Introduction}

Triclosan (TCS), or 5-chloro-2-(2,4-dichlorophenoxy)phenol, is a synthetic broad-spectrum antimicrobial developed in the 1960s. As a polychlorinated bisphenolic compound, TCS has a perceptible aromatic odor and is weakly soluble in water. It dissolves well in organic solvents including ethanol, dimethylsulfoxide (DMSO), and methanol [1], and the type of solvent and detergent availability seem to influence TCS activity [2-4]. For example, TCS dissolved in oils (e.g., olive oil) and alkali (e.g., sodium carbonate) exhibits markedly reduced efficacy when compared to other solvents such as glycerol and polyethylene glycol (PEG) $[3,5]$. In fact, using propylene glycol (PG) as a solvent renders TCS more effective than using PEG, which is probably due to micellar solubilization of TCS in the larger PEG molecules [3]. Recently, we have shown that the presence of nonionic detergents (e.g., Tween 20) inhibits TCS activity in vivo, most likely due to micelle formation [6]. In contrast, sodium dodecyl sulfate (SDS) has been reported to potentiate the antibacterial effect of TCS in vitro [7].

TCS has gained enormous popularity in commerce and in healthcare owing to its antibacterial, antiviral, and antifungal properties [8-10]. This efficacy has led to the widespread use of TCS as a preservative in a variety of consumer products, including cosmetics, soaps, mouthwashes, antiperspirants, kitchen utensils, clothing textiles, bedclothes, electronics, plastics, and toys (Triclosan White Paper prepared by the Alliance for the Prudent Use of Antibiotics (APUA)). In clinical practice, TCS is used as a disinfectant and an antiseptic in surgical sutures, scrubs, implants, and medical devices [11, 12]. Annual global production of TCS was estimated at 1500 tons [13], and a total of 132 million liters of TCS-containing products was consumed in a single year in the United States (Safety and Effectiveness of Consumer Antiseptics; Topical Antimicrobial Drug Products for Over-the-Counter Human Use; Proposed Amendment of the Tentative Final Monograph. 2013 https://www.fda.gov/downloads/ AboutFDA/ReportsManualsForms/Reports/EconomicAnalyses/ UCM379555.pdf).

The high demand for TCS has consequently led to substantial buildup in drinking and wastewater sources and, more alarmingly, accumulation in body fluids [14-20], establishing the antimicrobial as an environmental pollutant. Pharmacokinetic studies in man show that TCS reaches the 
systemic circulation by rapid absorption through the skin and mucous membranes of the oral cavity and gastrointestinal tract, and variations in the bioavailability of TCS unsurprisingly affect the rate of urinary excretion [21, 22]. TCS content in commercial products may reach as high as $17 \mathrm{mM}$ and comprise up to $1 \%$ of ingredients [12, 19, 23]. Moreover, absorption of up to $25 \%$ of applied TCS has been recorded [24], and metabolic studies in rats and mice revealed sulfation, glucuronidation, and hydroxylation products in tissues and excreta $[25,26]$.

Since the advent of TCS, early studies on the antiseptic have shown evidence of symptomatic relief from acne $[27,28]$ and contact dermatitis $[29,30]$ with fewer, or at least comparable, side effects to other therapeutic alternatives [31]. Later, TCS was found to be effective against crural ulcer [32] and chemically induced dermatitis and desquamation $[33,34]$, which could be attributed to its anti-inflammatory [35], hypoallergenic [36], and analgesic [37] properties. Moreover, a battery of studies collectively indicate that TCS is not a skin or oral mucosal irritant, has a very low sensitization potential ( $0.1-0.3 \%$ of 14,000 subjects), and is unlikely to be phototoxic to human skin (http://ec.europa.eu/health/ ph_risk/committees/04_sccp/docs/sccp_o_166.pdf). This is in contrast to the reversible skin and eye irritation caused by up to $10 \%$ TCS reported in animals (http://ec.europa.eu/ health/ph_risk/committees/04_sccp/docs/sccp_o_166.pdf). Also, in initial studies by Lyman and Furia, it was suggested that TCS is carcinogenic when orally administered to rats $[38,39]$. Subsequent investigations in rats and mice disclosed that TCS perturbs microsomal detoxification [40], causes nephrotoxicity and hepatotoxicity [41], reduces prenatal and postnatal survival [42], and leads to central nervous system suppression [43] and hypothermia [44]. In humans, the earliest description of an adverse TCS reaction probably comes from a case report of two patients who developed contact dermatitis following application of deodorants containing $0.12 \%$ and $0.2 \%$ TCS [45]. Since then, several case reports of the same ailment have thus far been in congruence [46-49]. It is important to mention that, as is the case with healthy subjects, in patients diagnosed with, or suspected to have, contact dermatitis, TCS was similarly found to have a very low sensitization potential (0.6-0.8\% of 11,887 patients) (http://ec.europa.eu/health/ph_risk/committees/04_sccp/ docs/sccp_o_166.pdf).

In light of the dichotomous debate surrounding TCS, the US Food and Drug Administration (FDA), following extensive examination of available data, has effectively banned antiseptic products containing TCS since September 2016 [19]. In Europe, TCS was approved for use in cosmetics by the European Community Cosmetic Directive in 1986 (http://ec.europa.eu/health/ph_risk/committees/04_sccp/ docs/sccp_o_166.pdf). However, the European Commission disapproved the use of TCS for hygienic purposes in 2017, but maintained its legality as a preservative in select cosmetics and mouthwashes in concentrations up to $0.3 \%$ and $0.2 \%$, respectively (http://ec.europa.eu/health/ scientific_committees/consumer_safety/docs/sccs_o_054.pdf; http://eur-lex.europa.eu/legal-content/EN/TXT/PDF/?uri= OJ:L:2014:107:FULL\&from=EN). Furthermore, the Scientific
Committee on Consumer Safety (SCCS) expressed its concern over the continued use of TCS in cosmetics, but not in antiseptics, mainly due to the cumulative pattern of exposure (http://ec.europa.eu/health/scientific_committees/ consumer_safety/docs/sccs_o_054.pdf). Importantly, the European Chemicals Agency (ECHA) classifies TCS, under the classification, labeling, and packaging (CLP) regulation, as an eye irritant 2 (causes serious eye irritation), skin irritant 2 (causes skin irritation), aquatic acute 1 (very toxic to aquatic life), and aquatic chronic 1 (very toxic to aquatic life with long-lasting effects) (https://echa.europa.eu/documents/10162/ 21680461/bpc_opinion_triclosan_pt1_en.pdf/efc985e4-88024ebb-8245-29708747a358). Because of the previously mentioned ecotoxic properties, TCS is currently a candidate for substitution under the Biocides European Union regulation (Reg 528/2012/EC) (https://echa.europa.eu/ potential-candidates-for-substitution-previous-consultations/-/ substance-rev/12/term?_viewsubstances_WAR_echarevsubsta nceportlet_SEARCH_CRITERIA_EC_NUMBER=222-1822\&_viewsubstances_WAR_echarevsubstanceportlet_DISS= true).

Our aim in this review is to provide an update on current knowledge regarding TCS therapeutic and toxic potential. Emphasis is placed on the biochemical and molecular alterations, either brought about by, or in response to, TCS exposure. Data from both in vitro and in vivo studies, obtained from humans and other organisms, are incorporated into the analysis, with special attention being given to reports published during the present decade.

\section{Membrane and Cytoskeletal Damage}

Perhaps the earliest report describing the antimicrobial activity of TCS was by Vischer and Regös [50] which was shown through topical application. In a follow-up study, TCS was found to be more effective with the broadest spectrum against bacteria and fungi when compared to other antimicrobials such as gentamicin and clotrimazole [10]. Subsequent efforts, which continue to this day, have focused on dissecting the diverse action mechanisms and cellular targets of TCS. Initially, it was thought that TCS interacts with the prokaryotic cell membrane nonspecifically [9]. This was corroborated by the resistance of Gram-negative bacteria to TCS, which was ascribed to their outer membrane [51, 52]. Investigating the genetic response of Mycobacterium tuberculosis to TCS, Betts et al. [53] identified perturbations in a wide assortment of genes involved in cell wall, transport, detoxification, and DNA replication and transcription. Also, Klebsiella pneumoniae with inactive efflux pump KpnGH exhibit pronounced susceptibility to multiple antibiotics including TCS [54]. Several genes in the membrane stress response pathway were also studied in Escherichia coli and Rhodospirillum rubrum S1H [55-57]. During the electro-Fenton transformation of TCS, significant changes in expression patterns of genes involved in cell wall and membrane structure, cell envelope, flagella, and multidrug efflux were observed (Table 1). These findings complement an earlier report describing enhanced resistance to TCS due to overexpressed $a c r A B$ multidrug efflux pump [58]. It was recently 
TABLE 1: Summary of membrane and cytoskeletal targets of TCS.

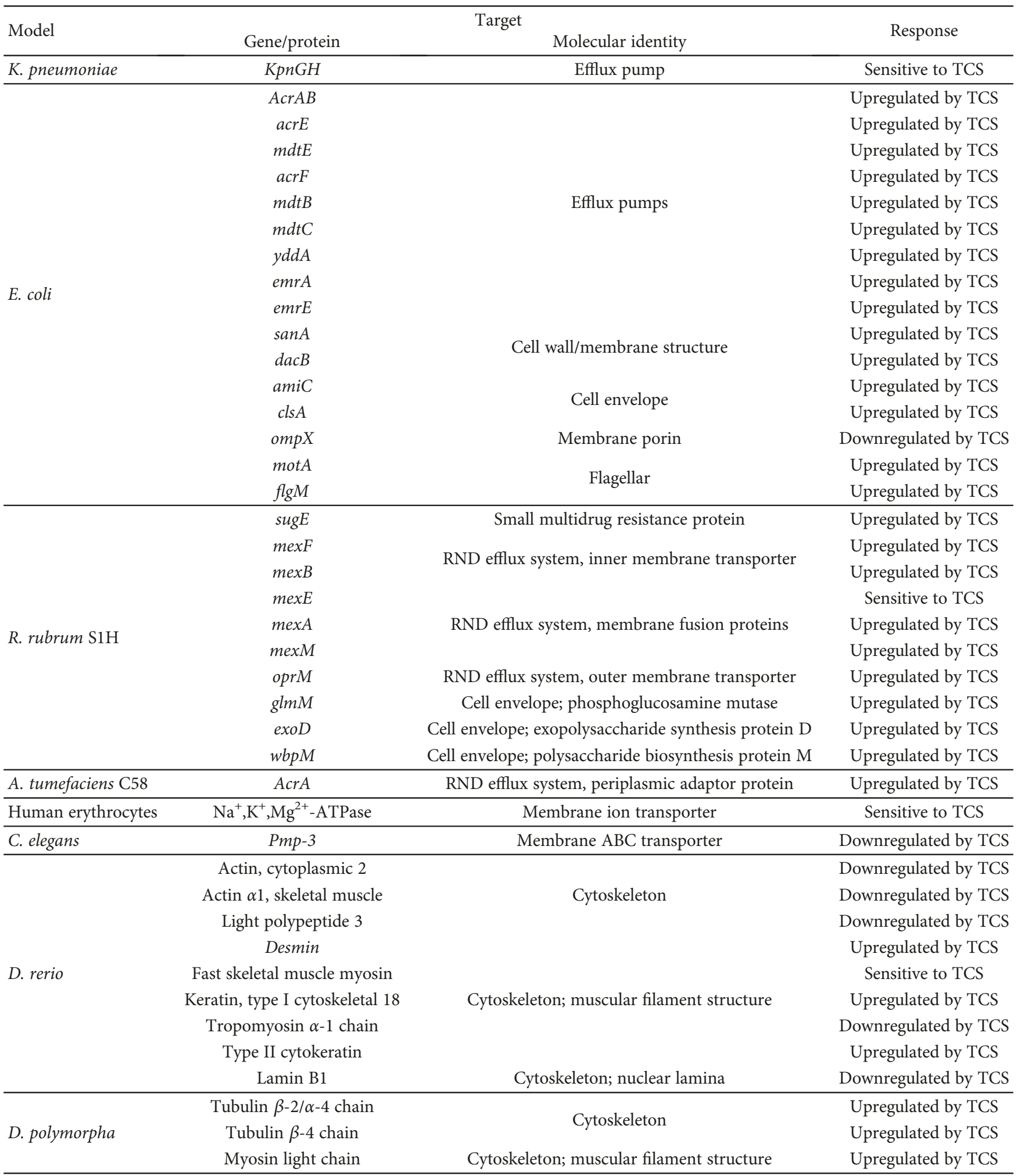

Abbreviation: RND: resistance-nodulation-division; ABC: ATP-binding cassette.

suggested that TCS binds to the transcriptional repressor AcrR, causing conformational changes and preventing its binding to the efflux pump AcrA promoter in Agrobacterium tumefaciens [59].
The interaction of TCS with the cell membrane was also studied in human red blood cells (RBCs; erythrocytes). TCS exposure led to $\mathrm{K}^{+}$leakage and overt hemolysis, indicating membrane damage, while antagonizing hypotonic lysis, 
which may be due to membrane expansion [60]. TCS also inhibited membrane-bound $\mathrm{Na}^{+}, \mathrm{K}^{+}, \mathrm{Mg}^{2+}$-ATPase enzymatic activity [61]. These observations suggest that TCS causes membrane destabilization, perturbs monovalent ion transport, and modulates the overall osmoregulation of erythrocytes. Evidence for membrane damage is further confirmed in numerous studies by means of compromised stability and permeability [62]. To directly observe how TCS interacts with the cell membrane, Guillén and coworkers utilized nuclear magnetic resonance (NMR) spectroscopy to demonstrate that TCS intercalates within hydrophobic pockets in the lipid bilayer, perpendicularly to phospholipid molecules [63]. Furthermore, using neutral red to evaluate membrane integrity, diminished uptake of the dye in hemocytes of the clam Ruditapes philippinarum and mussel Mytilus galloprovincialis was related to TCS-induced suppression of pinocytosis and disturbed phagocytosis [64, 65].

Along those lines, our recent findings indicate that TCS blunts the expression of the $p m p 3$ membrane transporter in Caenorhabditis elegans nematodes and that pmp3(ok1087) mutants exhibit increased sensitivity to the disinfectant [66]. Finally, a proteomic analysis of zebrafish (Danio rerio) larvae and gills of freshwater mussel Dreissena polymorpha revealed alterations in cytoskeletal protein levels following TCS exposure (summarized in Table 1) [67, 68].

There is a consensus in the literature regarding the membranotropic nature of TCS in different membrane models across various species. The cell membrane is a primary target for TCS and among the first cellular obstacles that must be overcome by the antiseptic to exert its effects. Although evidence implicating membrane-associated efflux pumps as part of the cellular response to TCS is strong, there is paucity in reports describing TCS modulation of structural or functional membrane components in human-based systems. Similarly lacking is an understanding of the role of membrane receptors not only in pumping out TCS molecules but also in transducing both inter- and intracellular signals as a consequence to TCS presence.

\section{Cellular Longevity}

The interest in TCS and ultimate cell fate has originally stemmed from its use in oral hygiene products, which is reflected in two seminal studies on human gingival cells $[69,70]$. TCS was shown to be cytotoxic to gingival fibroblasts and epithelial cells, identifying it as a novel stimulator of apoptosis in the latter.

Investigations have thus far followed a more comprehensive approach, relating cell death induced by TCS to other cellular adversaries, utilizing both human and non-human model systems. When TCS was treated to human choriocarcinoma placental cells (JEG-3), multiple dose- and timedependent responses were observed [71]. While there was a proportional increase in estradiol and progesterone secretion, $\beta$-human chorionic gonadotropin $(\beta$-hCG) release was nevertheless inhibited with increasing TCS concentrations [71]. In addition to blunted proliferation, significant cell death was recognized as apoptotic in nature evidenced by activated caspase- 3 and Hoechst 33342-stained fragmented DNA [71]. Similarly, using anoikis-resistant H460 human lung cancer cells, Winitthana et al. demonstrated that 24-hour exposure to $10 \mu \mathrm{M}$ TCS causes cell death and apoptosis. Nontoxic levels $(\leq 7.5 \mu \mathrm{M})$, however, enhanced cell growth (increased colony number and reduced size) without altering proliferation. TCS also promoted epithelial-tomesenchymal transition (EMT), along with the migratory and invasive abilities of the cells [72].

A research group performed a series of in vivo and in vitro studies on the effect of TCS on growth and proliferation of human BG-1 ovarian cancer cells. Results from these studies indicate that TCS increases cellular proliferation and both gene expression and protein levels of cyclin D1 and decreases p21 and Bax gene expression and protein levels [73]. These effects were significantly antagonized by the estrogen receptor (ER) antagonist ICI 182,780, implicating ER in TCS-induced cell cycle progression and in its antiapoptotic role. Investigators from the same group also reported a similar response to TCS by MCF-7 breast cancer cells and LNCaP prostate cancer cells. In MCF-7 cells, $1 \mu \mathrm{M}$ TCS enhanced growth and proliferation during a six-day period, which was associated with increased cyclin D1 and reduced p21 expression levels. When mice were treated with TCS for 8 weeks, brdU-positive breast tumor cells were significantly increased compared to the control group treated with corn oil [74]. Similar to BG-1 cells, TCS-promoted proliferation of MCF-7 cells was mediated through ER $\alpha$ signaling, demonstrated as antagonism by kaempferol and 3,3 ${ }^{9}$. diindolylmethane (DIM), two phytoestrogens [75]. In addition to cyclin D1 and p21, TCS caused an increase in cyclin E and a decrease in Bax and induced metastasis through elevated cathepsin $\mathrm{D}$ protein expression. These observations were paralleled in vivo using xenografted mouse models. Researchers from this report expanded their findings to VM7Luc4E2 cells, a variant of the MCF-7 model, to show that TCS $(0.1-10 \mu \mathrm{M})$ is pro-proliferative and antiapoptotic by inhibiting oxidative stress, with both effects being antagonized by kaempferol [76]. In LNCaP cells exposed to concentrations of TCS ranging from 0.01 to $10 \mu \mathrm{M}$ for up to 5 days showed enhanced proliferation and migration and reduced p21 protein expression [77]. In primary human syncytiotrophoblasts, TCS at 0.001 to $10 \mu \mathrm{M}$ induced apoptosis as seen by condensed nuclei and fragmented DNA [78]. TCS also reduced $11 \beta$-hydroxysteroid dehydrogenase type $2(11 \beta$ HSD2) via a caspase-dependent mechanism. Other targets included both Bax and Bcl-2 proteins.

Similar to human cells, both pro- and antiapoptotic properties were observed in rodent cells treated with TCS. Beside its cytotoxicity, TCS caused caspase-dependent apoptosis in rat neural stem cells along with elevated Bax and reduced $\mathrm{Bcl}-2$ [79]. In a series of studies, [80-82] mouse neurons were used to show that TCS is apoptotic through the Fas receptor (FasR), aryl hydrocarbon receptor (AhR), and caspase activation involving $\mathrm{N}$-methyl-D-aspartate receptors (NMDARs). In agreement with the cytotoxicity data, TCS-treated mouse lung epithelial cells were deformed with reduced viability [83]. Conversely, TCS stimulated the proliferation of mouse epidermis-derived JB6 $\mathrm{Cl}$ 41-5a cells, by increasing cyclins 
D1 and A and reducing p27(Kip1) protein levels [84]. Examining these effects in vivo, B6C3F1 mice exhibited epidermal hyperplasia and focal necrosis following topical administration of TCS. Moreover, the pluripotency markers of mouse embryonic stem cells were analyzed following TCS exposure [85]. Alkaline phosphatase (Alp), Sox2, Oct4, and Nanog were all reduced, while miRNA-134 was elevated.

Unlike human and rodent cells, in vivo and in vitro studies on aquatic organisms uniformly agree that TCS is solely proapoptotic in these animals. Pyknotic apoptosis in the central nervous system of zebrafish $D$. rerio was observed following treatment with either TCS alone or TCS combined with derivatives 2,4,6-trichlorophenol (2,4,6-TCP) and 2,4dichlorophenol (2,4-DCP) [86, 87]. The TCS-derivative mixture caused pronounced deformities and behavioral abnormalities and perturbed the expression of a panel of neurodevelopmental and apoptotic genes (Table 2). Also, TCS, following both in vivo and in vitro exposure, induced a dose- and time-dependent increase in apoptotic hemocytes of $D$. polymorpha $[88,89]$. Likewise, when the saltwater clam Ruditapes philippinarum was treated with TCS, hemocytes exhibited significant cell death, blunted proliferation, reduced size, and promiment apoptotic DNA fragmentation [65]. TCS-induced apoptosis, or apoptosis-like cell death, was also detected in unicellular organisms, such as the green alga Chlamydomonas reinhardtii and the pathogenic fungus Cryptococcus neoformans [90, 91].

Collectively, studies on TCS influence on cell fate indicate estrogenic, proliferative, and apoptotic activities. Genes and proteins governing the regulation of cell cycle and apoptosis are particularly sensitive to TCS modulation. The disparity in ultimate cell fate seems to point at an interspecies variation and a dose-specific response, among other experimental details such as cell type and duration of exposure. Elucidating the existence and the identity of a specific molecular "switch" that may tip the scales in favor of either cell death or survival could be an important inquiry for future investigations.

\section{Oxidative Stress}

Overwhelming evidence has recently accumulated in support of the prooxidative action of TCS. It is prudent to provide an overview of human-based studies first before summarizing notable findings obtained from other model organisms.

In Puerto Rican pregnant women, a correlation between exposure to TCS during pregnancy and oxidative damage, as measured by urinary 8 -hydroxyguanosine (8-OHdG), and inflammation was suggested [92]. Similar observations were also mirrored in Chinese and Brazilian children $[93,94]$. Conversely, in a global effort comprising nine countries from Asia, Europe, and North America, no relation between urinary TCS and 8-OHdG was established [95].

In vitro studies on human cells have also shed some light on the oxidative potential of TCS. In peripheral blood mononuclear cells (PBMC), 2,4-dichlorophenol (2,4-DCP)-a product of TCS transformation-promoted reactive oxygen species (ROS) generation, with subsequent lipid peroxidation and protein carbonylation [96]. Similarly, TCS caused elevated ROS in Nthy-ori 3-1 human follicular thyroid cells [97] and lipid peroxidation in retinoblastoma (Y79 RB) cells [98]. Our recent investigations on mesenchymal stem cells also showed TCS interference with the activation of nuclear factor (erythroid-derived 2)-like 2 (Nrf2), the "master regulator" of detoxification, and its downstream targets, heme oxygenase $1(\mathrm{HO}-1)$ and $\mathrm{NAD}(\mathrm{P}) \mathrm{H}$ dehydrogenase [quinone 1] (NQO-1) [66]. Consistently, TCS incorporated in mouthrinse did not exhibit antioxidant activity on fibroblasts [99]. In contrast, TCS reduced ROS levels in VM7Luc4E2 cells, which contributed to its antiapoptotic activity in these malignant breast cells [76].

Mitochondrial damage was also evident in multiple mammalian cells including human PBMC and keratinocytes, exposed to 3.5-350 $\mu \mathrm{M}$ TCS [100]. At concentrations up to $100 \mu \mathrm{M}$, TCS caused depolarization of mitochondrial membrane, reduced oxidative phosphorylation, and suppressed ATP synthesis. Weatherly et al. [101] utilized human HMC-1.2 mast cells and primary keratinocytes to show that TCS is a proton ionophore uncoupler and interferes with ATP production.

Animal studies conducted on mice and rats have revealed a profound response in the cellular antioxidant machinery upon TCS treatment. In rat thymocytes, superoxide anions were found to be elevated following TCS treatment [102] which, as Yueh et al. [103] showed, was met with increased expression of key antioxidant enzymes including HO-1, NQO-1, and glutathione S-transferase (GST) in mouse liver. Evidence for testicular DNA damage, elevated malondialdehyde (MDA), and superoxide dismutase (SOD), in addition to diminished catalase (CAT), was related to TCS treatment in weanling rats [104]. Similarly, in lung homogenates of female albino rats, TCS was found to induce lipid peroxidation and severely deplete the levels of other crucial antioxidants: SOD, CAT, and glutathione (GSH) [105]. Increased expression of glutathione peroxidase 1 (Gpxl) and aldehyde oxidase 1 (Aox1) was also observed as a consequence to TCS exposure in C57BL/6 mice [106]. Most recently, Zhang et al. [97] showed downregulation of antioxidant enzymes, Gpx3, Cat, and Sod2, along with elevated MDA, in the hypothalamus of Sprague-Dawley rats. Moreover, it was found that TCS treatment leads to increased ROS and reduced GSH activity in rat neural stem cells [79]. TCS also increased ROS levels in mouse neocortical neurons, along with perturbed regulation of cytochrome P450 family 1, subfamily a, member 1 (CYP1a1) and CYP1b1 [81, 82]. Effects of TCS on cytochromes and hepatic detoxification were also demonstrated in Sprague-Dawley rats, showing increased levels of UDP-glucuronosyltransferase 1-1 (Ugt1a), Ugt2b1, CYP1a1, CYP1a2, CYP2b1, CYP3a1, and sulfotransferase family $1 \mathrm{E}$ member 1 (Sult1e1) [97].

Several terrestrial organisms have been employed in the study of TCS toxicology. Caenorhabditis elegans is among the best-studied animal models due to its ease of maintenance and high genetic homology to humans. We have recently shown that TCS leads to overproduction of ROS, inhibition of nuclear translocation of protein skinhead-1 (SKN-1) antioxidant transcription factor, and 
TABLE 2: Summary of cell survival molecules modulated by TCS.

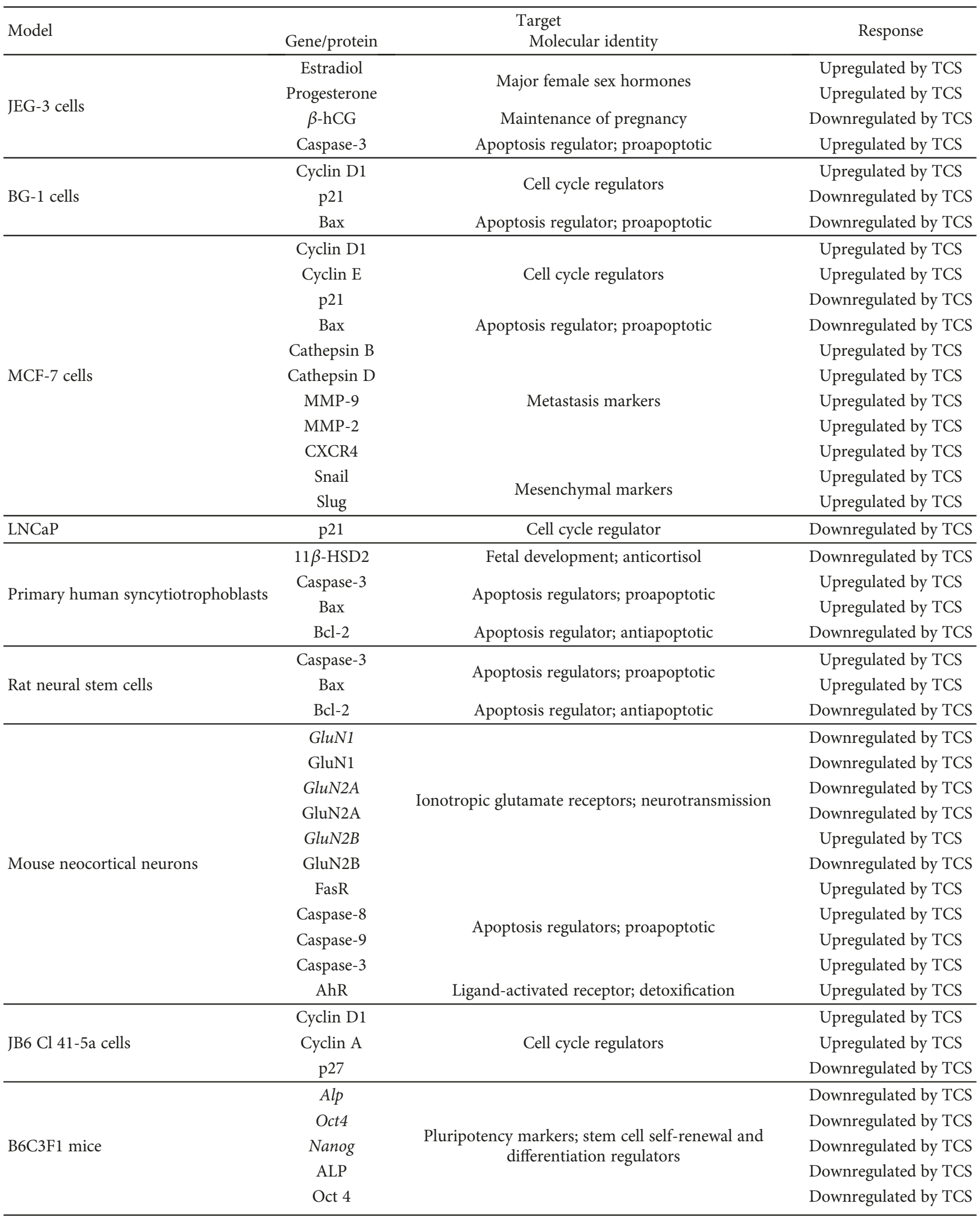


TABLE 2: Continued.

\begin{tabular}{|c|c|c|c|}
\hline \multirow{2}{*}{ Model } & \multicolumn{2}{|r|}{ Target } & \multirow{2}{*}{ Response } \\
\hline & Gene/protein & Molecular identity & \\
\hline & Nanog & & Downregulated by TCS \\
\hline & Sox 2 & & Downregulated by TCS \\
\hline & miRNA-134 & Transcriptional regulator of pluripotency markers & Upregulated by TCS \\
\hline \multirow{14}{*}{ D. rerio } & Oct4 & & Downregulated by TCS \\
\hline & Nanog & Pluripotency markers & Downregulated by TCS \\
\hline & Sox2 & & Upregulated by TCS \\
\hline & $p 53$ & Cell cycle regulator; tumor suppressor & Upregulated by TCS \\
\hline & Casp3 & \multirow{2}{*}{ Apoptosis regulators; proapoptotic } & Upregulated by TCS \\
\hline & Casp8 & & Upregulated by TCS \\
\hline & Shha & \multirow{4}{*}{ Early neurogenesis } & $\begin{array}{l}\text { Sensitive to TCS } \\
\text { sensitive to TCS }\end{array}$ \\
\hline & Ngn1 & & Upregulated by TCS \\
\hline & Nrd & & Upregulated by TCS \\
\hline & Elavl3 & & Upregulated by TCS \\
\hline & al-tubulin & \multirow{4}{*}{ Neural maturation } & Upregulated by TCS \\
\hline & Gap43 & & Upregulated by TCS \\
\hline & Gfap & & Downregulated by TCS \\
\hline & $M b p$ & & Downregulated by TCS \\
\hline
\end{tabular}

Abbreviation: Shha: sonic hedgehog a; Ngn1: neurogenin 1; Nrd: NeuroD; Elavl3: ELAV-like, neuron-specific RNA-binding protein 3; Gap43: growth-associated protein 43; Gfap: glial fibrillary acidic protein; Mbp: myelin basic protein.

downregulation of gamma-glutamyl cysteine synthetase (Gcs1) [66]. In a subsequent report, Skn1 expression was found to be upregulated by TCS along with Sod1, Sod4, heat shock proteins $(H s p)-3,-4,-16.2$, and -70 ; and cytochromes Cyp29A2 and Cyp34A9 (https://app.dimensions. ai/details/publication/pub.1103154992\#readcube-epdf). TCS also enhanced nuclear translocation of stress-related factor DAF-16, suggesting the occurrence of oxidative stress [107]. In the Earthworm Eisenia fetida, oxidative damage by TCS was manifested as a transient elevation in CAT and GST enzymes, increased MDA, and DNA damage [108]. In a follow-up study by the same group, SOD was also increased and decreased by TCS depending on the concentration used [109], a response mirrored by CAT in the snail Achatina fulica [110]. In that study, TCS caused diminished levels of SOD and peroxidase (POD), along with elevated MDA, among other morphological anomalies.

The ubiquity of TCS in aquatic environments has made animal models from that habitat the subject of extensive investigations on TCS toxicity. Perhaps the most relevant aquatic organism is the zebrafish $D$. rerio, owing to a strong structural and molecular resemblance to humans. Elucidating the interaction between TCS and the antioxidant system in ZFL liver cells, Zhou et al. [111] showed evidence of induced CYP1A activity along with a general trend of suppression in phase I and II detoxification enzymes. Elevated MDA, along with perturbed homeostasis of GSH, peroxiredoxin-2 (PRD-2), and HSPs, were observed in zebrafish larvae grown in the presence of TCS $([67,87])$.
TCS has been shown to induce MDA and cause oscillations in CAT, ethoxyresorufin-O-deethylase (EROD), erythromycin N-demethylase (ERND), and aminopyrine N-demethylase (APND) in Daphnia magna [112]. Moreover, elevated amino acids, including glutamine, glutamate, and proline, have been attributed to a general oxidative stress state in daphnids [113]. Also, stress-related proteins, including glyceraldehyde 3-phosphate dehydrogenase (GAPDH) and hsp-70, were modulated by TCS in D. polymorpha, in addition to lipid peroxidation [68]. TCS exposure demonstrated reduced oxyradicals and lipofuscin and elevated oxidized glutathione (GSSG) in the digestive gland of swollen river mussels Unio tumidus [114]. In Tigriopus japonicus copepods treated with TCS, increased ROS, SOD, GST, GPx, and GSH content was noted [115]. TCS also caused perturbations in expressional profiles of Cyps, Sod, Gst, and Cat proteins (Table 3) [115].

TCS treatment in the yellow catfish Pelteobagrus fulvidraco revealed induced CAT, EROD, ERND, and APND [116]. Expressional profiling of Cyp1a, Cyp3a, and Gst showed both up- and downregulation depending on TCS concentration and length of exposure, a pattern that was also seen with MDA formation. When another catfish, Heteropneustes fossilis, was treated with a cosmetic effluent rich in TCS, increased SOD and CAT activities and reduced GSH, GST, and GPx were noted [117].

Oxidative damage by TCS was also evident in the goldfish Carassius auratus, as MDA, CAT, and GSH were elevated in addition to a reduced total antioxidant capacity [118]. Variable responses by antioxidant enzymes and in MDA 
TABle 3: Oxidative stress patterns elicited by TCS.

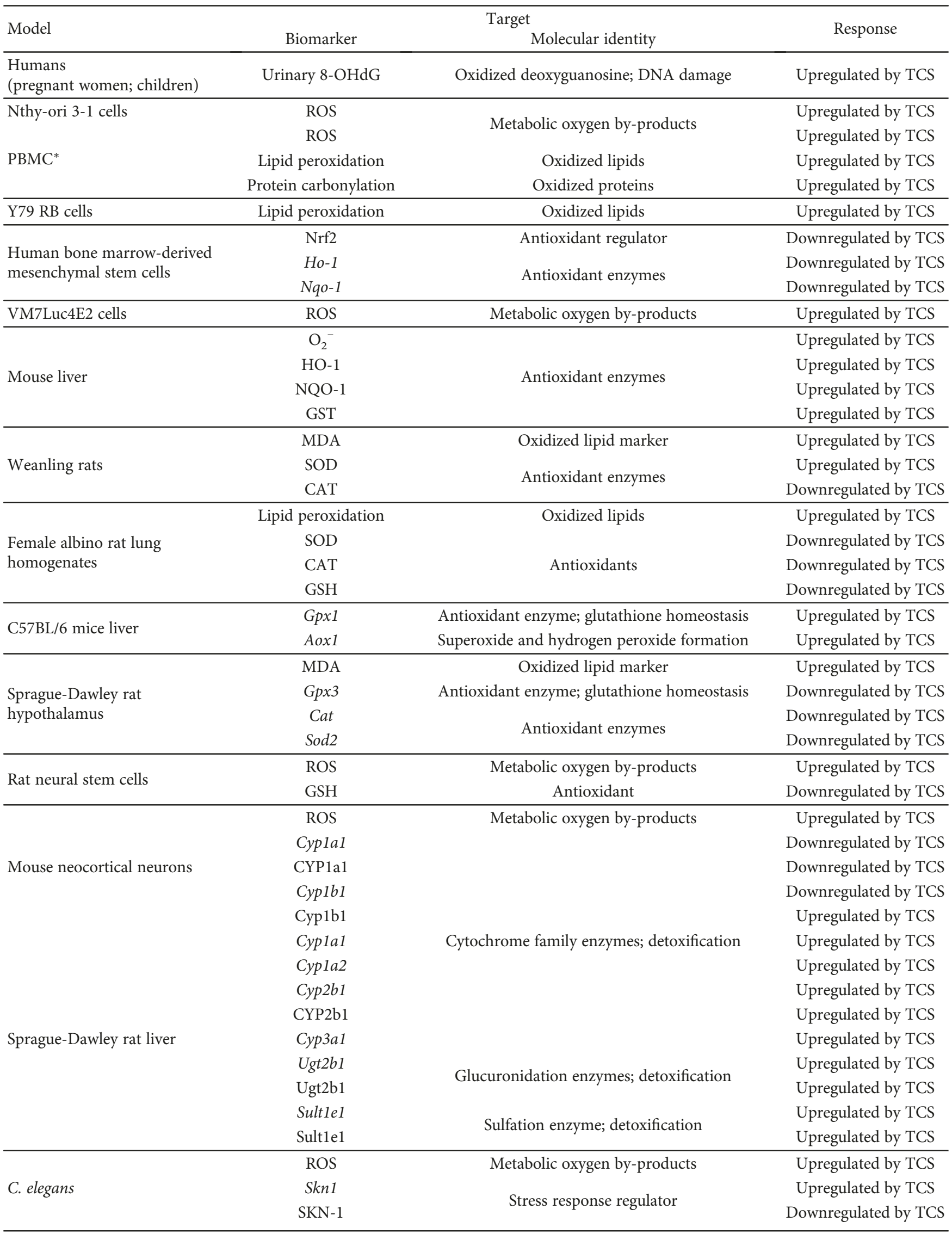


TABle 3: Continued.

\begin{tabular}{|c|c|c|c|}
\hline \multirow{2}{*}{ Model } & \multicolumn{2}{|r|}{ Target } & \multirow{2}{*}{ Response } \\
\hline & Biomarker & Molecular identity & \\
\hline & Gcs1 & & Downregulated by TCS \\
\hline & Sod1 & Antioxidant enzymes & Upregulated by TCS \\
\hline & Sod4 & & Upregulated by TCS \\
\hline & $H s p-3$ & & Upregulated by TCS \\
\hline & $H s p-4$ & & Upregulated by TCS \\
\hline & $H s p-16.2$ & Stress response; protein stabilization & Upregulated by TCS \\
\hline & Hsp-70 & & Upregulated by TCS \\
\hline & Cyp29A2 & & Upregulated by TCS \\
\hline & Cур 34 A9 & Cytochrome family enzymes; detoxification & Upregulated by TCS \\
\hline & DAF-16 & Stress response & Upregulated by TCS \\
\hline \multirow{4}{*}{ E. fetida } & MDA & Oxidized lipid marker & Upregulated by TCS \\
\hline & CAT & & Upregulated by TCS \\
\hline & GST & Antioxidant enzymes & Upregulated by TCS \\
\hline & SOD & & Sensitive to TCS to TCS \\
\hline \multirow{4}{*}{ A. fulica } & $\mathrm{MDA}$ & Oxidized lipid marker & Upregulated by TCS \\
\hline & CAT & & Sensitive to TCS to TCS \\
\hline & SOD & Antioxidant enzymes & Downregulated by TCS \\
\hline & POD & & Downregulated by TCS \\
\hline ZFL liver cells & CYP1A & Cytochrome family enzyme; detoxification & Upregulated by TCS \\
\hline \multirow{5}{*}{ D. rerio larvae } & GPx & & Upregulated by TCS \\
\hline & GR & Antioxidant enzymes; glutathione homeostasis & Downregulated by TCS \\
\hline & PRD-2 & Antioxidant enzyme & Downregulated by TCS \\
\hline & Hsp-5 & Stress resnonse. protein stabilization & Upregulated by TCS \\
\hline & Hsp-90 $\beta$ & Stress response; protein stabilization & Upregulated by TCS \\
\hline \multirow{8}{*}{ D. magna } & MDA & Oxidized lipid marker & Upregulated by TCS \\
\hline & CAT & Antioxidant enzymes & Sensitive to TCS to TCS \\
\hline & EROD & & Sensitive to TCS to TCS \\
\hline & ERND & Detoxification enzymes & Sensitive to TCS to TCS \\
\hline & APND & & Sensitive to TCS to TCS \\
\hline & Glutamine & & Upregulated by TCS \\
\hline & Glutamate & Amino acids; markers of protein & Upregulated by TCS \\
\hline & Proline & & Upregulated by TCS \\
\hline D. polymorpha gills & Hsp-70 & Stress response; protein stabilization & Sensitive to TCS to TCS \\
\hline \multirow{4}{*}{ U. tumidus digestive gland } & GAPDH & Oxidoreductase; glucose metabolism & Sensitive to TCS to TCS \\
\hline & GSSG & Oxidized glutathione; antioxidant & Upregulated by TCS \\
\hline & Oxyradicals & Oxygen-containing radicals; prooxidants & Downregulated by TCS \\
\hline & Lipofuscin & Lysosomal pigment granules; toxicity marker & Downregulated by TCS \\
\hline \multirow{10}{*}{ T. japonicus } & ROS & Metabolic oxygen by-products & Upregulated by TCS \\
\hline & Sod & \multirow{7}{*}{ Antioxidants; glutathione homeostasis } & Sensitive to TCS to TCS \\
\hline & SOD & & Upregulated by TCS \\
\hline & Cat & & Sensitive to TCS to TCS \\
\hline & Gst variants & & Sensitive to TCS to TCS \\
\hline & GST & & Upregulated by TCS \\
\hline & GPx & & Upregulated by TCS \\
\hline & GSH & & Upregulated by TCS \\
\hline & Cур3026а3 & \multirow{2}{*}{ Cytochrome family enzymes; detoxification } & Upregulated by TCS \\
\hline & Cyp3037a1 & & Upregulated by TCS \\
\hline
\end{tabular}


TABle 3: Continued.

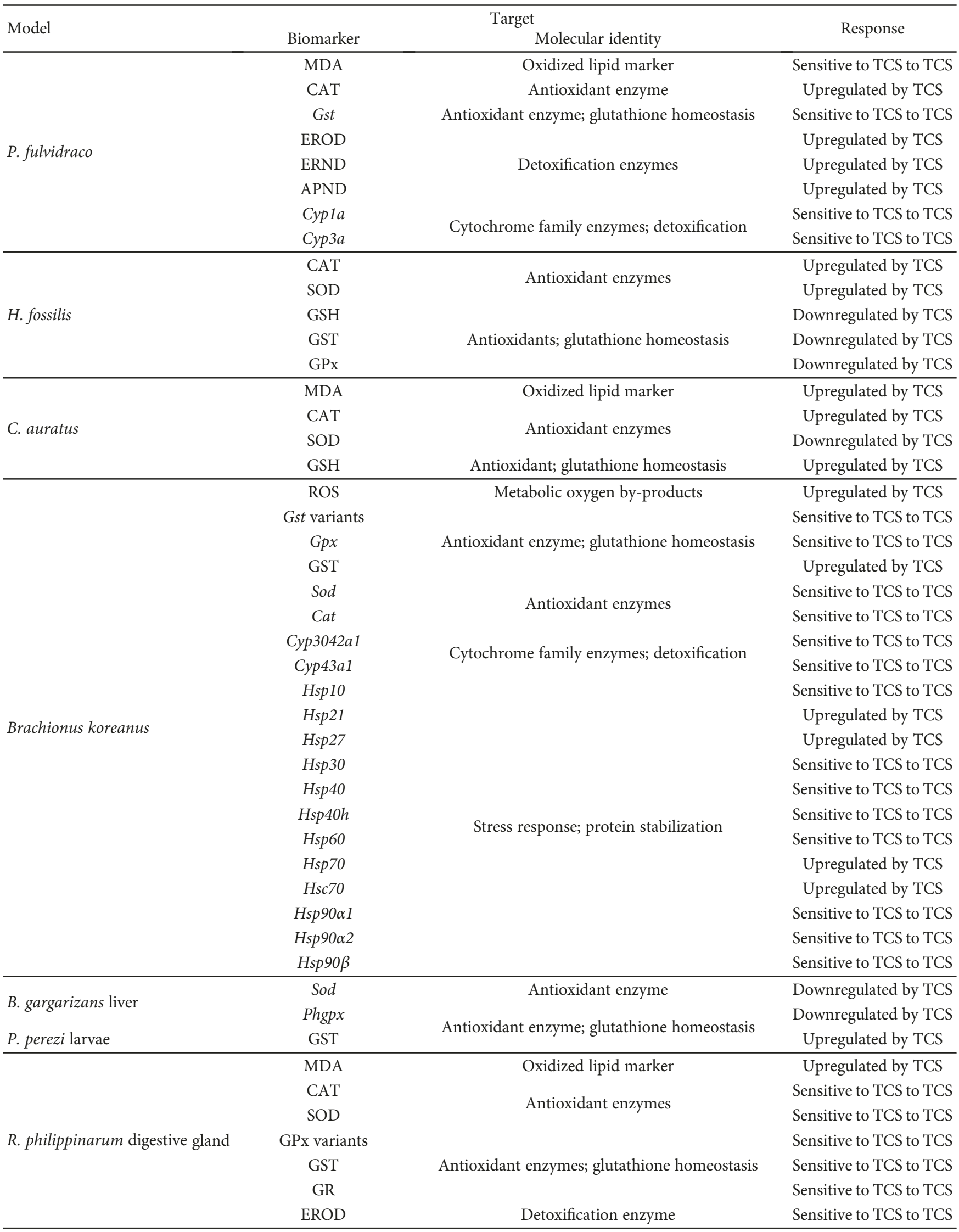


TABLE 3: Continued.

\begin{tabular}{|c|c|c|c|}
\hline \multirow{2}{*}{ Model } & \multicolumn{2}{|r|}{ Target } & \multirow{2}{*}{ Response } \\
\hline & Biomarker & Molecular identity & \\
\hline \multirow{7}{*}{ O. mykiss liver and kidney } & Cat & \multirow{2}{*}{ Antioxidant enzymes } & Downregulated by TCS \\
\hline & Sod & & Upregulated by TCS \\
\hline & $G p x$ variants & \multirow{2}{*}{ Antioxidant enzymes; glutathione homeostasis } & Upregulated by TCS \\
\hline & Gsta & & Upregulated by TCS \\
\hline & $H s p 90 b b$ & \multirow{3}{*}{ Stress response; protein stabilization } & Upregulated by TCS \\
\hline & Hsp90ba & & Upregulated by TCS \\
\hline & $H s c 70 a$ & & Upregulated by TCS \\
\hline \multirow{5}{*}{ C. reinhardtii } & ROS & Metabolic oxygen by-products & Upregulated by TCS \\
\hline & MDA & Oxidized lipid marker & Upregulated by TCS \\
\hline & Sod & Antioxidant enzyme & Upregulated by TCS \\
\hline & Gpx & \multirow{2}{*}{ Antioxidant enzyme; glutathione homeostasis } & Upregulated by TCS \\
\hline & Gpx & & Upregulated by TCS \\
\hline \multirow{9}{*}{ R. rubrum $\mathrm{S} 1 \mathrm{H}$} & GrxC & \multirow{2}{*}{ Antioxidant enzymes; glutathione homeostasis } & Upregulated by TCS \\
\hline & $\operatorname{Tr} x B$ & & Upregulated by TCS \\
\hline & OsmC & Antioxidant enzyme & Upregulated by TCS \\
\hline & DnaJ & Heat shock protein; general stress marker & Upregulated by TCS \\
\hline & RpoN & $\begin{array}{l}\text { RNA polymerase factor sigma-54; general stress } \\
\text { marker }\end{array}$ & Downregulated by TCS \\
\hline & $\operatorname{Ter} A$ & Tellurite resistance protein A; general stress marker & Upregulated by TCS \\
\hline & Psp variants & Phage shock proteins; general stress markers & Sensitive to TCS to TCS \\
\hline & $C l p P$ & $\begin{array}{l}\text { ATP-dependent protease, proteolytic subunit; general } \\
\text { stress marker }\end{array}$ & Upregulated by TCS \\
\hline & $H r c A$ & $\begin{array}{l}\text { Heat-inducible transcription suppressor; general } \\
\text { stress marker }\end{array}$ & Upregulated by TCS \\
\hline \multirow{5}{*}{ E. coli $\mathrm{K} 12$, MG1655 } & $O x y R$ & ROS sensor proteins & Upregulated by TCS \\
\hline & Grx & Antioxidant enzymes; glutathione homeostasis & Upregulated by TCS \\
\hline & Sod variants & \multirow{2}{*}{ Antioxidant enzymes } & Upregulated by TCS \\
\hline & Cat variants & & Upregulated by TCS \\
\hline & Ahp variants & Antioxidant enzymes & Upregulated by TCS \\
\hline \multirow{4}{*}{ E. coli } & ROS & Metabolic oxygen by-products & Upregulated by TCS \\
\hline & $Y g i W$ & \multirow{3}{*}{ Antioxidant proteins } & Downregulated by TCS \\
\hline & SoxS & & Downregulated by TCS \\
\hline & $Y h c N$ & & Downregulated by TCS \\
\hline
\end{tabular}

Abbreviation: TrxB: thioredoxin; OsmC: peroxiredoxin osmotically inducible protein C-like. * Effects of 2,4-DCP, a by-product of TCS degradation.

levels were recorded in the goldfish's liver after TCS treatment under a $\mathrm{pH}$ range of 6 to 9 [119]. The oxidative potential of TCS was also evident in the rotifer Brachionus koreanus, detected as ROS overproduction and enhanced GST activity, in addition to transcriptional modulation of cytochromes, antioxidant genes Gst, Gpx, Sod, and Cat and chaperons (Table 3) [120]. Moreover, TCS inhibited Sod and phospholipid hydroperoxide glutathione peroxidase (Phgpx) expression in the liver of Bufo gargarizans tadpoles [121] and induced GST in Pelophylax perezi frog larvae [122].

Sendra et al. [123] studied the combined effect of titanium dioxide $\left(\mathrm{TiO}_{2}\right)$ and a heterogeneous mixture of organic compounds including TCS using the clam Ruditapes philippinarum. Modulations in EROD, SOD, CAT, GPx, GST, and GR enzyme activities were noted in the clam's digestive gland, in parallel with increased lipid peroxidation. TCS exposure caused alterations in Cat, Sod, Gpx1, Gpx2, Gsta, $H s p 90 b b$, Hsp90ba, and $H s c 70 a$ genes in rainbow trout Oncorhynchus mykiss [124]. Although in one report TCS failed to elicit oxidative stress in the green algae Chlamydomonas reinhardtii [125], another report detected ROS formation following TCS exposure [90], which was also most recently confirmed by significantly increased MDA, downregulated Gpx, and upregulated Sod expression [126].

The antimicrobial nature of TCS makes bacteria an appropriate target for mechanistic studies. Using Rhodospirillum rubrum S1H, Pycke et al. [57] detected upregulation in a host of TCS-induced oxidative response genes, most 
notably Gpx. In E. coli K12, MG1655, the electro-Fenton transformation of TCS caused activation of genes related to ROS sensing, along with reduced glutaredoxin (Grx), Sod, Cat, and alkyl hydroperoxide reductase (Ahpr) [55]. Very recently, ROS formation by TCS was associated with diminished expression of antioxidants in E. coli (Table 3), an event that preceded mutagenesis and enhanced drug resistance in that species [56]. TCS was also recently used to validate novel self-luminescent bioreporter strains of Nostoc sp. PCC 7120 using Sod promoters [127].

Collectively, monumental evidence demonstrates the prooxidant properties of TCS evident as both overproduction of ROS and interference with the cellular antioxidant defensome. TCS is toxic in part by inducing oxidative damage in a wide range of organisms and by targeting a defined cluster of proteins in a fashion that is conserved among diverse species. Nonetheless, the vast majority of data are collected from non-human models, and, as is the case with other toxicological reports of TCS, studies conducted on man or human-derived tissues are severely lacking.

\section{Immunity and Inflammation}

TCS has, for a long time, been recognized as an effective therapy for infectious dermatitis [29-31], and the observed curative capacity of the compound was solely attributed to its antimicrobial activity. It was not until the end of last century that associations between TCS exposure and remission of noninfectious inflammation were made $[33,35,36]$, and the use of antibacterials as anti-inflammatory agents has gained deserved attention during the past two decades. For example, an appreciable number of antibiotics, including macrolides and quinolones, have been shown to possess antiinflammatory activity [128-132]. Follow-up efforts have successfully provided solid evidence for the direct interaction of TCS with inflammatory pathways.

Gaffar et al. [133] reported that TCS inhibits cyclooxygenase-1 (COX-1) and COX-2, 5-lipoxygenase and (LPO), 15-LPO, and interleukin- (IL-) $1 \beta$-induced prostaglandin E2 (PGE2) in gingival cells. TCS was also shown to suppress a wider range of inflammatory mediators including IL-1 $\beta$-induced prostaglandin I2 (PGI2) and arachidonic acid, tumor necrosis factor (TNF) $\alpha$-induced PGE2, phospholipase A2 (PLA2), and COX [134]. Moreover, in a doubleblind crossover study, participants who used a mouthrinse with added $0.15 \%$ TCS developed significantly less oral erythematous lesions than those who used a TCS-free mouthrinse [135]. By then, the anti-inflammatory properties of TCS were established and were widely accepted within the scientific and medical communities.

TCS in prosthetic devices was found to have no influence on the acute phase response [136], and only modest differences were seen between TCS and stannous fluoride dentrifice [137]. Nevertheless, TCS, when applied intracrevicularly, improved clinical parameters of gingivitis [138]. In a recent double-blind, randomized, crossover study, it was concluded that TCS-containing toothpaste inhibits inflammation in peri-implant tissue [139].
To date, elaborations on the anti-inflammatory nature of TCS have been the focus of subsequent studies. Mustafa et al. [140-142] identified IL-1 $\beta$, interferon (IFN) $\gamma$, major histocompatibility complex (MHC) class II, and PGE synthase-1, as targets of TCS in human gingival fibroblasts. Of note, studies to discern the subcellular localization of TCS show preference for nuclear, as opposed to cytosolic, accumulation. Although initial uptake was considerably higher in the cytoplasm, a great proportion of cytosolic TCS was eliminated after repeated washing, while nuclear retention was observed [143]. This may explain the perturbed inflammatory signaling associated with TCS. Moreover, in primary human oral epithelial cells, TCS attenuated LPS-induced cytokine response including IL-8, IL- $1 \alpha$, and $\mathrm{TNF} \alpha$ and aggravated the antimicrobial response, which was mediated through microRNA (miRNA) regulation of the toll-like receptor (TLR) pathway [144]. The findings were also reciprocated in cells derived from diabetic patients, with an exaggerated TLR response [145]. It was revealed that TCS, nevertheless, abrogated LPS-induced TLR response, again, through regulating miRNAs (stimulating miR146a and inhibiting miR155s).

In skin and leukocytes of mice topically treated with TCS, alterations in inflammatory responses were mediated through TLR4 [146]. Likewise, TCS downregulated parathyroid hormone- (PTH-) or PGE2-stimulated matrix metalloproteinase-13 (MMP-13) expression in rat osteoblastic osteosarcoma cells [147]. Since hyperactive MMP-13 is implicated in periodontal disease, it was suggested that TCS might have a protective role against oral inflammatory conditions through its action on that enzyme, among others [148].

Interestingly, favorable results have been observed for TCS against other inflammatory conditions including cardiovascular disease and hidradenitis suppurativa $[149,150]$. Moreover, the use of TCS-impregnated ureteral stents seems to be a promising approach to combat urinary tract infections (UTI) and associated inflammation [151, 152]. Along those lines, an increased urinary TCS was related to increased serum IL-6 in pregnant women [92], pointing at a possible pro- or anti-inflammatory role.

In a unique effort by Barros et al. [153], TCS modulation of the inflammatory response in an ex vivo whole blood stimulation assay was investigated. In that study, TCS inhibited multiple inflammatory mediators induced by LPS, including interleukins, most notably IL-1 \& IL-6, IFNs, and colonystimulating factor (CSF) 2. Activation of type $1 \mathrm{~T}$ helper lymphocytes was interrupted through the action of TCS on CD70. In a related report, TCS also reduced the capacity of natural killer (NK) lymphocytes to lyse chronic myelogenous leukemia K562 cells [154]. Recently, chitosan-TCS particles reduced the expression of IL- $1 \beta$-induced Cox 2 and Il6, among other immune molecules in gingival fibroblasts (Table 4) [155], showcasing the vast amenability of this antimicrobial to nanoparticle manipulation.

Other in vivo studies on rodents and marine organisms clarified further the immunomodulatory properties of TCS. For instance, in mice subjected to an acute, systemic E. coli infection, Sharma et al. [156] demonstrated that cotreatment with TCS significantly reversed the damage caused by the 
TABLE 4: Inflammatory and immune mediators responsive to TCS.

\begin{tabular}{|c|c|c|c|}
\hline \multirow{2}{*}{ Model } & \multicolumn{2}{|r|}{ Target } & \multirow{2}{*}{ Response } \\
\hline & Biomarker & Molecular identity & \\
\hline \multirow{14}{*}{ Human gingival fibroblasts } & $\mathrm{COX}-1 / 2$ & \multirow{7}{*}{ Inflammatory mediators } & Downregulated by TCS \\
\hline & $5 / 15-\mathrm{LPO}$ & & Downregulated by TCS \\
\hline & PGE2 & & Downregulated by TCS \\
\hline & PGI2 & & Downregulated by TCS \\
\hline & Arachidonic acid & & Downregulated by TCS \\
\hline & PLA2 & & Downregulated by TCS \\
\hline & PGE synthase-1 & & Downregulated by TCS \\
\hline & $\mathrm{IFN} \gamma$ & \multirow{2}{*}{ Immune/inflammatory cytokines } & Downregulated by TCS \\
\hline & IL- $1 \beta$ & & Downregulated by TCS \\
\hline & MHC II & Cell surface proteins; adaptive immunity regulators & Downregulated by TCS \\
\hline & $\operatorname{Cox} 2$ & Inflammatory mediator & Downregulated by TCS \\
\hline & Il6 & \multirow{2}{*}{ Immune/inflammatory cytokines } & Downregulated by TCS \\
\hline & $I l 1 b$ & & Downregulated by TCS \\
\hline & Tlr6 & Innate immunity receptor & Upregulated by TCS \\
\hline \multirow{5}{*}{ Human primary oral epithelial cells } & IL-8 & \multirow{5}{*}{ Transcriptional regulators of TLR response } & Downregulated by TCS \\
\hline & IL- $1 \alpha$ & & Downregulated by TCS \\
\hline & $\mathrm{TNF} \alpha$ & & Downregulated by TCS \\
\hline & miR146a & & Upregulated by TCS \\
\hline & $\operatorname{miR} 155 s$ & & Downregulated by TCS \\
\hline \multirow{6}{*}{ Mouse skin and leukocytes } & S100A8/A9 & Inflammatory modulator; $\mathrm{Ca}^{2+}$-binding protein & Upregulated by TCS \\
\hline & Tlr4 & \multirow{5}{*}{ Innate immunity receptors } & Upregulated by TCS \\
\hline & TLR4 & & Upregulated by TCS \\
\hline & Tlr1 & & Upregulated by TCS \\
\hline & Tlr2 & & Upregulated by TCS \\
\hline & Tlr6 & & Upregulated by TCS \\
\hline Rat osteoblastic osteosarcoma cells & MMP-13 & Endopeptidase; collagen degradation & Downregulated by TCS \\
\hline \multirow{7}{*}{ Human oral fluids } & $\mathrm{IL}-1 \alpha$ & \multirow{3}{*}{ Immune/inflammatory cytokines } & Downregulated by TCS \\
\hline & IL- $1 \beta$ & & Sensitive to TCS \\
\hline & IL-8 & & Sensitive to TCS \\
\hline & MCP-1 & \multirow{3}{*}{ MMP regulator proteins } & Sensitive to TCS \\
\hline & TIMP-2 & & Sensitive to TCS \\
\hline & TIMP-1 & & Downregulated by TCS \\
\hline & MMP-8/9 & Endopeptidases; extracellular matrix degradation & Downregulated by TCS \\
\hline Human urine & IL-6 & \multirow{3}{*}{ Immune/inflammatory cytokines } & Upregulated by TCS \\
\hline \multirow{2}{*}{ Sprague-Dawley rats } & $\mathrm{TNF} \alpha$ & & Upregulated by TCS \\
\hline & IL-6 & & Upregulated by TCS \\
\hline \multirow{11}{*}{ Human whole blood leukocytes } & $\operatorname{Csf2}$ & Hematopoietic stem cell growth and maintenance & Downregulated by TCS \\
\hline & Ifnal & \multirow{10}{*}{ Immune/inflammatory cytokines } & Downregulated by TCS \\
\hline & Ifna2 & & Downregulated by TCS \\
\hline & Ifna4 & & Downregulated by TCS \\
\hline & Ifna8 & & Downregulated by TCS \\
\hline & Il-1f10 & & Downregulated by TCS \\
\hline & Il-1f5 & & Downregulated by TCS \\
\hline & Il-1f7 & & Downregulated by TCS \\
\hline & Il-1f8 & & Downregulated by TCS \\
\hline & Il-1f9 & & Downregulated by TCS \\
\hline & Il-6 & & Downregulated by TCS \\
\hline
\end{tabular}


TABLE 4: Continued.

\begin{tabular}{|c|c|c|c|}
\hline \multirow{2}{*}{ Model } & \multicolumn{2}{|r|}{ Target } & \multirow{2}{*}{ Response } \\
\hline & Biomarker & Molecular identity & \\
\hline & Il-11 & \multirow[b]{7}{*}{ Cell surface receptor/ligand; activated lymphocytes } & Downregulated by TCS \\
\hline & Il-13 & & Downregulated by TCS \\
\hline & Il-25 & & Downregulated by TCS \\
\hline & Il-19 & & Downregulated by TCS \\
\hline & $I l-21$ & & Downregulated by TCS \\
\hline & Il-9 & & Downregulated by TCS \\
\hline & $C d 70$ & & Downregulated by TCS \\
\hline & $B m p 2$ & \multirow{2}{*}{ Growth factors; bone and cartilage development } & Upregulated by TCS \\
\hline & Bmp6 & & Upregulated by TCS \\
\hline & Tnfrsf $11 b$ & \multirow[t]{2}{*}{ TNFSF11 receptor } & Downregulated by TCS \\
\hline & Gdf3 & & Downregulated by TCS \\
\hline & $G d f 2$ & \multirow{3}{*}{ Growth/differentiation factors } & Downregulated by TCS \\
\hline & Gdf5 & & Downregulated by TCS \\
\hline & Gdf9 & & Downregulated by TCS \\
\hline & Inhba & Hypothalamus-pituitary axis regulator & Downregulated by TCS \\
\hline & Lefty 2 & $\begin{array}{l}\text { Left-right determination factor } 2 \text {; } \\
\text { left-right asymmetry of organs }\end{array}$ & Downregulated by TCS \\
\hline \multirow{2}{*}{ Sprague-Dawley rats } & TNF $\alpha$ & \multirow{2}{*}{ Immune/inflammatory cytokine } & Upregulated by TCS \\
\hline & IL-6 & & Upregulated by TCS \\
\hline
\end{tabular}

Abbreviation: MCP: monocyte chemoattractant protein; TIMP: tissue inhibitor of metalloproteinase; Bmp: bone morphogenetic protein; Gdf: growth differentiation factor; Inhba: inhibin beta A chain.

bacteria. Specifically, TCS prolonged survival; lessened hepatic congestion, hemorrhage, and fatty changes; and reduced blood liver enzymes, serum $\mathrm{TNF} \alpha$, and the severity of bacteremia. In accordance with published data, TCS was similarly immunosuppressive in aquatic mussels (M. galloprovincialis) and clams (R. philippinarum) $[64,65]$.

Contrary to the overwhelming evidence of the antiinflammatory function of TCS, a number of studies have nonetheless identified a proinflammatory role by the antiseptic. For example, upon intratracheal instillation of TCS in Sprague-Dawley rats, elevated total cell (TC) count, polymorphonuclear leukocytes (PMNs), total protein (TP), LDH, TNF $\alpha$, and IL-6 were observed in bronchoalveolar lavage (BAL) fluid [83], which, except for TP, returned to baseline levels 14 days after exposure. Consonantly, it has also been demonstrated that TCS exacerbates diethylnitrosamine-induced hepatocellular carcinoma in C57BL/6 mice [103]. Likewise, TCS was very recently found to increase Tlr4 expression to promote colitis and aggravate colitis-related cancer in C57BL/6 mice [157].

It is evident from the wealth of information present that TCS is a modulator of immune and inflammatory reactions. The sum of data from in vitro and in vivo studies indicates that TCS, on its own, is immunosuppressive. Nevertheless, increasing evidence seems to suggest that in the presence of an existing adverse condition, such as inflammation or tumor, TCS further potentiates and worsens the eventual outcome. Investigations into the molecular basis behind this unique behavior are particularly warranted.

\section{Genotoxicity and Carcinogenicity}

Among the most important aspects of toxicological profiling of compounds is their interaction with the molecule of lifethe DNA. Early efforts $[42,158]$ point at a possible role for TCS in somatic mutations observed in mice. TCS also caused a significant reduction in global DNA methylation in human hepatocellular carcinoma HepG2 cells, a finding associated with liver tumor [159]. Similarly, TCS caused a doseresponsive increase in chromosomal aberrations in lung fibroblast V79 cells, but not in ovary CHO cells, of the Chinese hamster Cricetulus griseus [12]. In a comparative study on Drosophila melanogaster using three mouthwashes, namely, Cepacol ${ }^{\circledR}$ (0.05\% cetylpyridinium chloride), Perio$\operatorname{gard}^{\circledR}(0.12 \%$ chlorhexidine digluconate $)$, and $\mathrm{Plax}^{\circledR}(0.03 \%$ TCS), it was concluded that only the ethanol content in $\mathrm{Cepacol}^{\circledR}$, but not other active ingredients, caused mitotic recombination between homologous chromosomes [160]. On the other hand, TCS induced dose-responsive DNA damage in hemocytes of the zebra mussel D. polymorpha [88], and strand breaks in the digestive gland of $U$. tumidus mussels [114]. A similar dose-dependent DNA damage was also observed in the earthworm E. fetida [108, 109], but not in E. andrei [161].

Comparing TCS to other toxicants in the larvae of freshwater insect Chironomus riparius, Martinez-Paz et al. [162] found TCS, along with nonylphenol, to be the most potent in causing DNA breakage. It was also noted that TCS, either alone or in combination with carbendazim, induced DNA 
TABLE 5: TCS genotoxicity and carcinogenicity.

\begin{tabular}{|c|c|c|}
\hline Model & Effect & Classification \\
\hline HepG2 cells & Global DNA hypomethylation & \\
\hline V79 cells & Chromosomal aberrations & \\
\hline Mouse & $\begin{array}{l}\text { Somatic mutation (positive spot test) } \\
\text { Increased incidence of liver tumors } \\
\text { Aggravated hepatocellular carcinoma } \\
\text { Exacerbated colon tumorigenesis }\end{array}$ & Limited evidence of carcinogenicity \\
\hline D. polymorpha & DNA damage (positive comet assay) & \\
\hline U. tumidus & DNA strand breaks (Hoescht 33342 fluorescence) & \\
\hline E. Fetida & DNA damage (positive Comet assay) & \\
\hline D. magna & DNA damage (positive Comet assay) & \\
\hline A. salina & DNA damage (positive Comet assay) & \\
\hline H. fossilis & DNA damage (positive Comet assay) & N/A \\
\hline C. auratus & DNA damage (positive Comet assay) & \\
\hline O. mykiss & DNA damage (positive Comet assay) & \\
\hline T. thermophila & DNA damage (positive Comet assay) & \\
\hline A. сера & $\begin{array}{l}\text { Chromosomal stickiness, reduced mitotic activity, and ana-telophase bridges } \\
\text { (positive Feulgen reaction) }\end{array}$ & \\
\hline
\end{tabular}

$\mathrm{N} / \mathrm{A}=$ data from non-mammalian animals are not considered for ECHA mutagenicity/carcinogenicity classification.

damage in D. magna [163]. Using the brine shrimp Artemia salina, a time-dependent pattern of TCS-induced genotoxicity was identified [164]. Moreover, TCS was genotoxic in the catfish Heteropneustes fossilis, goldfish C. auratus, and rainbow trout $O$. mykiss $[117,118,124]$. Importantly, when TCS at an environmentally relevant concentration (3nM) was treated to the freshwater protozoan Tetrahymena thermophila, notable DNA damage, without significant perturbation in growth or cell viability, was evident [165]. In a more detailed study on E. coli, Gou et al. [55] revealed that the electro-Fenton transformation of TCS caused upregulation of a host of genes involved in the DNA repair machinery, indicative of DNA stress. These genes belong to base excision repair ( $m u t T$ and $n f o$ ), nucleotide excision repair ( $u v r A$ and $u v r D$ ), mismatch repair ( $u v r D$ and $s s b$ ), and double-strand break repair $(s s b$ and $\operatorname{rec} N)$. Chromosomal stickiness, reduced mitotic activity, and ana-telophase bridges were also noticeable in the bulb onion Allium cepa following TCS treatment [166].

In a recent proof-of-concept study, the promising potential of a toxicogenomic approach as a follow-up to positive in vitro genotoxicity data was evaluated. Using TCS as a testing compound, it was shown that the antimicrobial is non-DNA reactive and that it is genotoxic solely in vitro as opposed to in vivo [167].

Ambiguity surrounding the carcinogenicity of TCS still remains today. Investigators have generally been able to provide evidence for carcinogenic effects in animal models but not in humans. Of the earliest studies in this regard was a report by Lyman and Furia [38] identifying TCS as a carcinogen in mice. Other studies on mice have been in agreement with that conclusion. For example, it was noted that chronic TCS exposure increased the incidence of liver neoplasms [12] and aggravated hepatocellular carcinoma [103]. Furthermore, TCS caused colonic inflammation and worsened colitis or tumorigenesis induced by dextran sodium sulfate [168]. These findings, were, however, not paralleled in rats, hamsters, or baboons [12, 169]. More importantly, in vivo human studies of TCS are scarce, and aspects related to TCS-induced oncogenesis are lacking. Consequently, whether TCS poses a carcinogenic hazard to humans is unknown and requires further investigation. Nonetheless, the interaction of TCS with human-derived cancer cells in vitro has recently gained considerable attention (reviewed under Therapeutic Proposals).

In light of available data (Table 5), TCS demonstrates carcinogenicity solely in mice and within a narrow range of tissues (the liver and colon), which constitutes limited evidence of carcinogenicity according to ECHA (https://echa.europa.eu/documents/10162/23036412/clp_en. pdf/58b5dc6d-ac2a-4910-9702-e9e1f5051cc5). Hence, TCS is not classifiable as a carcinogen (http://ec.europa.eu/ health/scientific_committees/consumer_safety/docs/sccs_o_ 054.pdf). It must be noted that in case future assessment conclusively rules out TCS as a human carcinogen, caution with its use must still be exercised given the established carcinogenicity of its transformation products-dioxins, chloroform, and anilines [170].

\section{Cellular Signaling}

Adaptations to the ever-changing intracellular and surrounding environments are achieved, in large part, by effective communication. Transmission of information that carries specific instructions is executed by messengers that function in tandem within a defined pathway. Tasks, however, are usually accomplished through the sequential transduction of multiple messages along a complex, intertwining network that involves a wide assortment of mediators [171]. Hence, the participation of cell signaling cascades in the response to xenobiotics cannot be overlooked. 
The use of human cell lines has provided a wealth of information particularly regarding the study of signaling molecules responsive to stressors and xenobiotics, including TCS. In H460 lung cancer cells, TCS promoted migration and invasion through focal adhesion kinase/ATP-dependent tyrosine kinase (FAK/Akt) and Ras-related C3 botulinum toxin substrate 1 (Rac1) [72]. Evidence similarly exists for the classical mitogen-activated protein kinases (MAPK) as targets of TCS. For example, proliferation of JB6 Cl 41-5a cells as induced by TCS was accompanied by activation of extracellular signal-regulated kinases 1/2 (ERK1/2), c-Jun $\mathrm{N}$-terminal kinases (JNK), and p38 MAPKs, in addition to Akt [84]. Importantly, blocking either MEK1/2 or phosphoinositide 3-kinase (PI3K) significantly attenuated TCSinduced proliferation. In another study on rat neural stem cells, TCS-induced cytotoxicity and apoptosis were accompanied by activation of p38 and JNK and suppression of ERK, Akt, and PI3K [79]. This points at the involvement of these proteins in both cellular survival and death as brought about by TCS. Recently, TCS was shown to activate p38 and JNK in vivo as detected in the hypothalamus of Sprague-Dawley rats and in vitro utilizing human Nthy-ori 3-1 thyroid follicular cells [97]. In that study, TCS stimulated the thyrotropinreleasing hormone receptor through p38 MAPK, which, in turn, influenced the thyroid peroxidase (TPO) level.

In suppressing TLR signaling in whole blood leukocytes, TCS downregulated the expression of several signaling mediators, most notably, NF- $\kappa \mathrm{B}$-inducing kinase (Nik) and $C$-jun, which accounted for the overall blunted inflammatory response to LPS in these cells [153]. Furthermore, suppression of Mmp-13 expression in mouse osteoblastic osteocarcinoma cells by TCS was possibly related to its inhibition of Fos/Jun and AP-1 sequence binding in both the Mmp-13 and $C$-fos promoters [147].

The endocrine-disrupting activity of TCS, specifically its estrogenicity, has been of great interest to researchers. Kim et al. [73] utilized BG-1 ovarian cancer cells to show that the proliferative effects of TCS were mediated through ER $\alpha$. Confirming the ER's role, the use of ICI 182,780 reversed the proliferative properties of TCS along with associated perturbations in cyclin D1, p21, and Bax expression and protein levels. Likewise, the ER is implicated in TCS-induced proliferation of MCF-7 cells and increased breast tumor mass in mice $[74,75,172]$. This was similarly indicated by TCS inhibition with ICI 182,780 or kaempferol and the stimulation of insulin-like growth factor (IGF) signaling, namely, phosphorylated insulin receptor substrate (pIRS-1), pAkt, pMEK1/2, and pERK1/2 [75]. Notably, kaempferol also inhibited TCS-induced VM7Luc4E2 cell growth [76]. These observations are in congruence with an earlier report by Huang et al. [173] describing the estrogenic activities of nanomolar concentrations of TCS in the same cells. Investigating ER-responsive genes on the transcriptional and translational levels, it was shown that TCS induced pS2 but blunted ER $\alpha$ mRNA and protein levels, the latter of which was related to elevated miR-22, miR-206, and miR-193b miRNAs.

Recent studies have also argued for the dual effect of TCS on ER signaling. For example, Henry and Fair [174] demonstrated that, when administered alone to MCF7 cells, TCS at $7 \mathrm{nM}$ to $700 \mu \mathrm{M}$ exhibits estrogenic activity but becomes antiestrogenic in the presence of E2. Along those lines, it was shown that TCS, on its own, lacked any effect on rat uterine growth, but could still potentiate the effect of ethinylestradiol (EE) [175]. In a follow-up investigation, it was reported that TCS promotes EE-induced inhibition of $\mathrm{ER} \alpha$ and $\mathrm{ER} \beta$ expression and when given alone does not activate ER at concentrations from $30 \mathrm{nM}$ to $100 \mu \mathrm{M}$ [176]. Furthermore, TCS diminished E2 and estrogen sulfotransferase in sheep placenta [177]. This is in contrast to the increased activity of ER $\beta$ but not ER $\alpha$ caused by a TCS-derivative mixture, which led to neurological and behavioral abnormalities in zebrafish [87]. Also, Sprague-Dawley rats given TCS showed increased uterine weight and Calbindin-d(9k) (CaBP-9k) expression, which was also reciprocated in pituitary GH3 cells [178]. Reversal of both anomalies by ICI 182,780 and RU 486 points at a possible estrogenic role of the antimicrobial.

Very recently, Serra et al. [179] challenged accumulating evidence of TCS estrogenicity by showing the lack of agonistic or antagonistic effect in vivo and in vitro. While up to $0.3 \mu \mathrm{M}$ TCS did not modulate ER-dependent brain aromatase in zebrafish embryos, interference with the enzyme's activity, and with E2 activation of the enzyme observed at $1 \mu \mathrm{M}$, was not attributed to TCS-ER interaction. Moreover, up to $10 \mu \mathrm{M}$ TCS lacked estrogenic effects in ER-expressing zebrafish liver cells as well as in MCF-7 cells [179]. Additionally, in a screening study of the estrogenicity of a group of endocrine-disrupting chemicals on fish species, TCS failed to significantly elicit a response in an in vitro $\mathrm{ER} \alpha$ reporter gene assay [180].

In light of available evidence, the general consensus seems to indicate that the estrogenicity of TCS is contingent upon multiple factors, including concentration, species, duration of exposure, and whether TCS is administered alone or in combination with other molecules.

With regard to the androgenic properties of TCS, it was revealed that TCS interferes with testosterone- (TSN-) related transcription but promotes that dependent on androgen $[181,182]$. In a recent in vivo study on weanling male rats, Riad et al. [104] reported that TCS, either alone or combined with butylparaben, reduced TSN, leutinizing hormone (LH), and follicle-stimulating hormone (FSH), while increased E2 was observed upon single TCS administration Also, TCS-induced proliferation and migration of LNCaP cells were significantly reduced in presence of bicalutamide, an androgen receptor (AR) antagonist [77]. These findings support a previous report by Ahn et al. [183] in which $1 \mu \mathrm{M}$ TCS reduced E2-induced ER activation by $50 \%$ and $\mathrm{AR}$ in human BG1Luc4E2 ovarian adenocarcinoma cells and T47D-ARE breast cancer cells, respectively. Evidence for TCS estrogenicity was detected in MCF7 cells when $[(3) \mathrm{H}]$ estradiol was successfully displaced from the ER by the antimicrobial [184]. Furthermore, $10 \mu \mathrm{M}$ TCS attenuated E2-dependent ERE-CAT reporter gene induction, while 0.1 and $1 \mu \mathrm{M}$ TCS inhibited TSN-stimulated LTR-CAT reporter gene in both T47D cells and S115 mouse mammary tumor cells [184]. TCS was also determined to have a weak 
effect on AhR in recombinant rat hepatoma (H4L1.1c4) cells. Finally, Forgacs et al. [185] showed that TCS interferes with recombinant hCG stimulation of TSN in a novel BLTK1 murine Leydig cell model. Most recently, however, no significant influence on androgen synthesis or activity by TCS was observed in Wistar rats [186].

Controversy surrounding the interaction between TCS and members of the peroxisome proliferator-activated receptors (PPARs) has gained considerable attention as of late. This has essentially stemmed from the apparent discrepancy between data obtained from humans and those from rodents. In comparing the differential modulation of TCS on PPAR $\alpha$ in HepG2 cells and mouse hepatoma Hepa1c1c7 cells, distinct responses were observed by Wu et al. [187]. Protein levels of PPAR $\alpha$ downstream target, acyl-coenzyme A oxidase, were decreased in HepG2 cells but were increased in Hepa1c1c7, which also showed higher DNA synthesis and blunted apoptosis through transforming growth factor (TGF- $\beta$ ). PPAR signaling was similarly identified as a target of TCS through genome-wide CRISPR-Cas9 screening in HepG2 cells [188], zebrafish [189], and Gallus gallus chicken embryos [190]. In the latter model, PPAR signaling members Cyp7a1, fatty acid-binding protein 1 (Fabpl), acyl-CoA synthetase long-chain family member 5 (Acsl5), acyl-CoA oxidase 2 (A $\operatorname{cox} 2)$, and perilipin 1 (Plin1) were upregulated, whereas angiopoietin-like 4 (Angptl) was downregulated.

TCS administered to pregnant mice caused insulin resistance, hypothyroidism, diminished glucose transporter 4 (GLUT4) expression, and inhibition of Akt and mTOR phosphorylation [191, 192]. While thyroxine corrected these adversaries, PPAR $\gamma$ activator, rosiglitazone, solely reversed the decrease in Akt phosphorylation in adipose tissue and in muscle [192]. PPAR $\gamma$ is known to ameliorate mTOR suppression-induced glucose intolerance in rats [193], further underlining the far-reaching effects of TCS action.

Although TCS has been reported to promote hepatocyte proliferation in mice through PPAR [12], Yueh et al. [103] found no appreciable induction of PPAR $\alpha$ following TCS treatment. Importantly, the authors also identified constitutive androstane receptor (CAR) as a possible aggravator of TCS-induced tumorigenesis, given the halved tumor number in $\mathrm{Car}^{-/-}$mice compared to their $\mathrm{Car}^{+/-}$counterparts. TCS, as is the case with PPARs, is reported to exhibit varying affinities for CAR and pregnane $\mathrm{X}$ receptor (PXR) in humans and rodents. A weak agonist for human CAR, TCS was found to be a reverse agonist for rodent CAR, an agonist for human PXR, and had no effect on rodent PXR [194].

Calcium concentration within cells influences protein conformation and dynamics. Protein binding of $\mathrm{Ca}^{2+}$, on the other hand, maintains the ion's content within a physiological range and sets forth diverse cellular activities related to gene expression, motility, secretion, and survival [195]. Beside proteins, intracellular $\mathrm{Ca}^{2+}$ levels are modulated by a variety of stimuli, including xenobiotic exposure. Through the $\mathrm{Ca}^{2+}$ channel ryanodine (Ry) receptor type 1 (RyR1), TCS increased cytosolic $\mathrm{Ca}^{2+}$ dose-dependently in primary skeletal myotubes irrespective of extracellular $\mathrm{Ca}^{2+}$ [183]. Accordingly, muscle contractility was compromised upon
TCS exposure in vitro and in vivo [196]. Results from this study indicate that TCS impaired excitation-contraction coupling (ECC) in cardiac and skeletal muscles and enhanced electrically induced $\mathrm{Ca}^{2+}$ transients in myotubes without depleting intracellular $\mathrm{Ca}^{2+}$ and notwithstanding RyR1 blockage. TCS also efficiently blocked excitationcoupled $\mathrm{Ca}^{2+}$ entry and interfered with the bidirectional signaling between RyR1 channels and $\mathrm{Ca}^{2+}$ ions. Likewise, TCS compromised ECC in larval fathead minnows Pimephales promelas, as evidenced by altered RyR and dihydropyridine receptor (DHPR) mRNA and protein levels and weakened ligand binding to both receptors in adult muscle homogenates [197].

In rat thymocytes, TCS elevated intracellular $\mathrm{Ca}^{2+}$ levels and opened $\mathrm{Ca}^{2+}$-responsive $\mathrm{K}^{+}$channels, eventually leading to membrane hyperpolarization [198]. Also, TCS prevented $\mathrm{Ca}^{2+}$-induced mitochondrial swelling in rat liver [199]. A more in-depth analysis of TCS modulation of $\mathrm{Ca}^{2+}$ homeostasis was conducted on rat basophilic leukemia (RBL) mast cells [24]. In this cell type, TCS caused mitochondrial fission and diminished membrane potential and translocation, with compromised ATP production and elevated ROS. These changes were associated with perturbed mitochondrial and endoplasmic reticulum $\mathrm{Ca}^{2+}$ and depleted cytosolic $\mathrm{Ca}^{2+}$ levels following antigen stimulation. Accordingly, TCS-induced degranulation of mast cell may at least in part be attributed to $\mathrm{Ca}^{2+}$ mobilization.

Calcium modulation by TCS has also been investigated in other organisms. In C. reinhardtii exposed to $14 \mu \mathrm{M}$ TCS, increased $\mathrm{Ca}^{2+}$ levels with oxidative stress, cell and mitochondrial membrane depolarization, compromised photosynthesis, and caspase activation were noted [90]. Importantly, chelation of intracellular $\mathrm{Ca}^{2+}$ ions by BAPTA-AM protected the algae from TCS-induced $\mathrm{Ca}^{2+}$ dysregulation. These observations strongly implicate $\mathrm{Ca}^{2+}$ as a mediator of a wide array of toxic anomalies attributed to TCS.

Literature concerning the xenobiotic response to TCS has revealed important signaling pathways activated or suppressed by TCS (Table 6). Distinct outcomes exist among species and even within the same species based on experimental conditions and model under investigation. Although important milestones in TCS signaling have been achieved so far, there remains a lot to be discovered, especially in human-based systems, about the modulatory effects of TCS on cellular physiology. In particular, the response of many human cell types and tissues to TCS treatment is unknown, and identification of signaling pathways and their roles in cellular growth, metabolism, and overall function is therefore advised.

\section{Therapeutic Proposals}

The first specific action mechanism of TCS in prokaryotes was only demonstrated 20 years ago, when inhibition of fatty acid synthesis in Escherichia coli was noted following exposure to TCS [200, 201]. TCS irreversibly inhibited the fatty acid biosynthesis enzyme, enoyl-acyl carrier protein reductase (ACP), by mimicking its natural substrate in vivo. 
TABLE 6: TCS modulation of signaling pathways.

\begin{tabular}{|c|c|c|c|}
\hline \multirow{2}{*}{ Model } & \multicolumn{2}{|r|}{ Target } & \multirow{2}{*}{ Response } \\
\hline & Pathways & TCS role & \\
\hline \multirow{2}{*}{ H460 cells } & FAK/Akt & \multirow{2}{*}{ Cellular migration and invasion } & Upregulated by TCS \\
\hline & Rac1 & & Upregulated by TCS \\
\hline \multirow{5}{*}{ JB6 Cl 41-5a cells } & ERK1/2 & \multirow{5}{*}{ Cell proliferation } & Upregulated by TCS \\
\hline & JNK & & Upregulated by TCS \\
\hline & p38 & & Upregulated by TCS \\
\hline & Akt & & Upregulated by TCS \\
\hline & PI3K & & Upregulated by TCS \\
\hline \multirow{6}{*}{ Rat neural stem cells } & JNK & \multirow{6}{*}{ Cytotoxicity and apoptosis } & Upregulated by TCS \\
\hline & p38 & & Upregulated by TCS \\
\hline & ERK & & \\
\hline & Akt & & Downregulated by TCS \\
\hline & PI2K & & Downregulated by TCS \\
\hline & PIJK & & Downregulated by TCS \\
\hline \multirow{2}{*}{$\begin{array}{l}\text { Sprague-Dawley rats hypothalamus } \\
\text { and Nthy-ori 3-1 cells }\end{array}$} & JNK & \multirow{2}{*}{ Reduced TPO; hypothyroidism } & Upregulated by TCS \\
\hline & p38 & & Upregulated by TCS \\
\hline \multirow{2}{*}{ Whole blood leukocytes } & Nik & & Downregulated by TCS \\
\hline & Cjun & & Downregulated by TCS \\
\hline \multirow{3}{*}{ Mouse osteoblastic osteocarcinoma } & Fos & Anti-inflammatory response & Downregulated by TCS \\
\hline & Jun & & Downregulated by TCS \\
\hline & Ap1 & & Downregulated by TCS \\
\hline BG-1 & $\mathrm{ER} \alpha$ & & Upregulated by TCS \\
\hline \multirow{5}{*}{ MCF-7 cells } & $\mathrm{ER} \alpha^{*}$ & & Sensitive to TCS \\
\hline & pIRS-1 & & Upregulated by TCS \\
\hline & pAKT & & Upregulated by TCS \\
\hline & pMEK1/2 & & Upregulated by TCS \\
\hline & pERK1/2 & & Upregulated by TCS \\
\hline \multirow{7}{*}{ VM7Luc4E2 cells } & $E r \alpha$ & Cell proliferation & Downregulated by TCS \\
\hline & Ps2 & & Upregulated by TCS \\
\hline & $\mathrm{ER} \alpha$ & & Downregulated by TCS \\
\hline & pS2 & & Upregulated by TCS \\
\hline & miR-22 & & Upregulated by TCS \\
\hline & miR-206 & & Upregulated by TCS \\
\hline & $\operatorname{miR}-193 b$ & & Upregulated by TCS \\
\hline \multirow{2}{*}{ Sheep placenta } & E2 & & Downregulated by TCS \\
\hline & Estrogen sulfotransferase & Anti-estrogenicity & Downregulated by TCS \\
\hline BG1Luc4E2 cells & $\mathrm{ER}^{*}$ & & Downregulated by TCS \\
\hline Sprague-Dawley rats and GH3 cells & CaBP-9 k & Estrogenicity & Upregulated by TCS \\
\hline $\mathrm{LNCaP}$ & $\mathrm{AR}$ & Androgenicity; cell proliferation, and migration & Upregulated by TCS \\
\hline T47D-ARE cells & $\mathrm{AR}$ & Anti-androgenicity & Downregulated by TCS \\
\hline H4L1.1c4 cells & $\mathrm{AR}$ & Pro(anti)-androgenicity & Sensitive to TCS \\
\hline HepG2 cells & Acyl-coenzyme A oxidase & Blunted lipid metabolism & Downregulated by TCS \\
\hline \multirow{2}{*}{ Hepalc1c7 cells } & Acyl-coenzyme A oxidase & Enhanced lipid metabolism and DNA synthesis & Upregulated by TCS \\
\hline & TGF- $\beta$ & Antiapoptosis & Downregulated by TCS \\
\hline \multirow{2}{*}{ D. rerio } & $\operatorname{PPAR} \alpha$ & & Upregulated by TCS \\
\hline & $\operatorname{PPAR} \gamma$ & Enhanced lipid metabolism & Upregulated by TCS \\
\hline G. gallus embryo livers & $\operatorname{PPAR} \alpha$ & & Upregulated by TCS \\
\hline
\end{tabular}


TABLE 6: Continued.

\begin{tabular}{lccc}
\hline Model & Pathways & Target & TCS role \\
\hline ICR mice & Akt & Response \\
\hline C57BL/6 mice & CAR & Impaired glucose metabolism & $\begin{array}{r}\text { Downregulated by TCS } \\
\text { Downregulated by TCS }\end{array}$ \\
\hline HepG2 cells & CAR & Tumorigenesis & Upregulated by TCS \\
\hline Rodent FAO hepatoma cells & PXR & Enhanced hepatic catabolism & Upregulated by TCS \\
\hline Primary skeletal myotubes & CAR & Reduced hepatic catabolism & Upregulated by TCS \\
\hline P. promelas muscle homogenates & $\mathrm{Ca}{ }^{2+}$ & Downregulated by TCS \\
\hline Rat thymocytes & $\mathrm{RyR} 1$ & Upregulated by TCS \\
\hline RBL cells & $R y r 2$ & Upregulated by TCS & Sensitive to TCS \\
\hline C. reinhardtii & $R y r 3$ & Diminished muscle contractility & Downregulated by TCS \\
\hline
\end{tabular}

${ }^{*}$ TCS is anti-estrogenic in the presence of E2.

Further, a mutated or overexpressed ACP, encoded by fabI, was shown to confer TCS resistance in the bacterium. These findings established ACP as a specific, subcellular TCS target. Efforts have thus far revealed the susceptibility of a host of other pathogens to inhibition of fatty acid synthesis by TCS. These include Staphylococcus aureus, M. tuberculosis, Helicobacter pylori, Haemophilus influenzae, Plasmodium falciparum, Toxoplasma gondii, Leishmania spp., and Trypanosoma spp. [52, 202-208]. In humans, fatty acid synthase (FAS) is the only multienzyme complex that is responsible for the endogenous synthesis of saturated fatty acids from acetyl-CoA and malonyl-CoA [209, 210]. Although a BLAST analysis of $E$. coli FabI protein and FAS showed no homology, appreciable sequence similarities were nevertheless found with polyketide synthase and type I FAS of $M$. tuberculosis [211].

The success of cerulenin, a mycotoxin with fatty acid inhibitory action, in suppressing tumor progression in vivo has spawned several reports in support of fatty acid synthesis inhibition as an emerging target for chemotherapy [212]. The earliest study in this regard investigated the cytotoxicity of TCS in MCF-7 and SKBr-3 breast cancer cells [211]. It was revealed that TCS at $10-50 \mu \mathrm{M}$ is cytotoxic and antiproliferative, induces morphological alterations, and inhibits FAS. These findings corroborate an earlier observation linking FAS inhibition with apoptotic death of breast cancer cells $[211,213,214]$. TCS was similarly found to inhibit the development of methylnitrosourea-induced breast cancer in Sprague-Dawley rats [209]. In human A-375 melanoma cells, TCS inhibited growth at $40 \mu \mathrm{M}$ [215]. TCS was similarly found to be dose-dependently proapoptotic in prostate cancer cells, with $\mathrm{IC}_{50}$ values as low as 4.5$7.8 \mu \mathrm{M}$ [216]. Whereas no cytotoxicity was observed in NIH3T3 fibroblasts at concentrations up to $60 \mu \mathrm{M}$, values of $\mathrm{IC}_{50}$ ranging from 0.74 to $62 \mu \mathrm{M}$ were nonetheless observed in nonmalignant prostate cells. This suggests two things; first, that prostate cells are relatively more sensitive to TCS toxicity than fibroblasts and presumably other nonmalignant cell types, and second, that malignant prostate cells exhibit higher chemosensitivity compared to their nonmalignant counterparts. This differential susceptibility could be due to overexpressed FAS in malignant cells. However, in contrast to these reports, at concentrations up to $345 \mu \mathrm{M}$, TCS was found to be preferentially cytotoxic to Y79 RB cells over mouse 3T3 fibroblasts and human MIO-M1 Müller glial cells as indicated by $\mathrm{IC}_{50}$ values, creating a large therapeutic index of 7.1 and 5.3, respectively [217]. FAS suppression, depleted fatty acid content, lipid peroxidation, and apoptotic death were noted in Y79 RB cells at the same TCS concentration range [98]. Recently, TCS at $40 \mu \mathrm{M}$ was also shown to be effective against $\mathrm{MiaPaCa}-2$ and AsPC-1 pancreatic cancer cells suppressing proliferation and eliciting apoptotic death [218]. Of note, in a related study, TCS impeded mouse preadipocyte differentiation [219]. Given the regulation of food intake by FAS, and the susceptibility of adipocyte development to TCS inhibition, it was suggested that TCS may possess anti-obesogenic properties.

The differential expression and activity of FAS in healthy and malignant tissues, where it is upregulated in the latter [220, 221], indicate a possibly high therapeutic index. The long history of human use, and the ubiquity of TCS in consumer products, coupled with encouraging in vivo results, cements the antimicrobial as a promising candidate for chemotherapy. As noted earlier, it must be stressed that variations in the final outcome of TCS treatment largely depend on experimental setup. Moreover, limited data from animal studies suggest that in the presence of a preexisting tumor, TCS administration seems to exacerbate the condition. This observation is concerning and indeed warrants further investigation before TCS can be invested in for clinical trials. 


\section{Conclusion}

TCS is a synthetic antimicrobial with a long history of human use. At concentrations well below those present in commercial products, data from in vitro and in vivo studies have provided evidence of adverse effects on diverse molecular pathways. Most alarmingly is TCS enhancement of malignant cell proliferation in vitro and tumor growth in vivo. On the other hand, TCS has also been shown to be protective against malignant cell growth and proliferation, possibly opening the door for its use in chemotherapy. Clearly, dose and time dependence is an important factor in determining the eventual denouement of the chemical. In spite of the numerous publications dissecting the signaling pathways responsive to TCS, it is evident that a severe paucity surrounding human-based in vivo and in vitro studies still remains today. Future studies, thus, should focus on identifying signaling molecules differentially regulated by TCS and characterize their roles in toxic or protective effects in different cell types. Insights gained from such revelations will be invaluable to possibly validate targets for drug development or devise possible TCS adjuvants or inhibitors.

\section{Conflicts of Interest}

The authors declare that there are no conflicts of interest regarding the publication of this paper.

\section{Acknowledgments}

We thank the members of the Lee Laboratory for helpful advice and discussion during this work. This work was supported in part by the Brody Brothers Grant (BBE216102), NIH (1R15AG060373-01) to M-H.L., and the Saudi Government Graduate Scholarship (through King Saud University) to M.A.A.

\section{References}

[1] R. Montville and D. W. Schaffner, "A meta-analysis of the published literature on the effectiveness of antimicrobial soaps," Journal of Food Protection, vol. 74, no. 11, pp. 18751882, 2011.

[2] V. Kjaerheim, A. Skaare, P. Barkvoll, and G. Rolla, "Antiplaque, antibacterial, and anti-inflammatory properties of triclosan mouthrinses in combination with zinc citrate or polyvinylmethylether maleic acid (PVM-MA) copolymer," European Journal of Oral Sciences, vol. 104, no. 5-6, pp. 529-534, 1996.

[3] V. Kjaerheim, S. M. Waaler, and G. Rolla, "Organic solvents and oils as vehicles for triclosan in mouthrinses: a clinical study," Scandinavian Journal of Dental Research, vol. 102, no. 5, pp. 306-308, 1994.

[4] A. B. Skaare, V. Kjaerheim, P. Barkvoll, and G. Rolla, "Does the nature of the solvent affect the anti-inflammatory capacity of triclosan? An experimental study," Journal of Clinical Periodontology, vol. 24, no. 2, pp. 124-128, 1997.

[5] V. Kjaerheim, S. M. Waaler, and G. Rolla, "Significance of choice of solvents for the clinical effect of triclosancontaining mouthrinses," Scandinavian Journal of Dental Research, vol. 102, no. 4, pp. 202-205, 1994.
[6] M. A. Alfhili, D. S. Yoon, T. A. Faten et al., "Non-ionic surfactants antagonize toxicity of potential phenolic endocrinedisrupting chemicals, including Triclosan in Caenorhabditis elegans," Molecules and Cells, vol. 41, no. 12, pp. 10521060, 2018.

[7] S. M. Waaler, G. Rölla, K. K. Skjörland, and B. Ögaard, "Effects of oral rinsing with triclosan and sodium lauryl sulfate on dental plaque formation: a pilot study," Eropean Journal of Oral Sciences, vol. 101, no. 4, pp. 192-195, 1993.

[8] K. Bellamy, R. Alcock, J. R. Babb, J. G. Davies, and G. A. J. Ayliffe, "A test for the assessment of 'hygienic' hand disinfection using rotavirus," The Journal of Hospital Infection, vol. 24, no. 3, pp. 201-210, 1993.

[9] J. Regos and H. R. Hitz, "Investigations on the mode of action of Triclosan, a broad spectrum antimicrobial agent," Zentralblatt fur Bakteriologie, Parasitenkunde, Infektionskramkheiten und hygiene, Erste Abteilung Originale, Reihe A: Medizinische Mikrobiologie und Parasitologie, vol. 226, no. 3, pp. 390-401, 1974.

[10] J. Regös, O. Zak, R. Solf, W. A. Vischer, and E. G. Weirich, "Antimicrobial spectrum of triclosan, a broad-spectrum antimicrobial agent for topical application. II. Comparison with some other antimicrobial agents," Dermatologica, vol. 158, no. 1, pp. 72-79, 1979.

[11] R. C. Petersen, "Triclosan antimicrobial polymers," AIMS Molecular Science, vol. 3, no. 1, pp. 88-103, 2016.

[12] J. V. Rodricks, J. A. Swenberg, J. F. Borzelleca, R. R. Maronpot, and A. M. Shipp, "Triclosan: a critical review of the experimental data and development of margins of safety for consumer products," Critical Reviews in Toxicology, vol. 40, no. 5, pp. 422-484, 2010.

[13] X. Chen, J. L. Nielsen, K. Furgal, Y. Liu, I. B. Lolas, and K. Bester, "Biodegradation of triclosan and formation of methyl-triclosan in activated sludge under aerobic conditions," Chemosphere, vol. 84, no. 4, pp. 452-456, 2011.

[14] M. Adolfsson-Erici, M. Pettersson, J. Parkkonen, and J. Sturve, "Triclosan, a commonly used bactericide found in human milk and in the aquatic environment in Sweden," Chemosphere, vol. 46, no. 9-10, pp. 14851489, 2002.

[15] T. Geens, H. Neels, and A. Covaci, "Distribution of bisphenol-A, triclosan and n-nonylphenol in human adipose tissue, liver and brain," Chemosphere, vol. 87, no. 7, pp. 796-802, 2012.

[16] L. Hovander, T. Malmberg, M. Athanasiadou et al., "Identification of hydroxylated PCB metabolites and other phenolic halogenated pollutants in human blood plasma," Archives of Environmental Contamination and Toxicology, vol. 42, no. 1, pp. 105-117, 2002.

[17] L. W. B. Olaniyan, N. Mkwetshana, and A. I. Okoh, "Triclosan in water, implications for human and environmental health," Springerplus, vol. 5, no. 1, p. 1639, 2016.

[18] J. Schulze, F. H. Marquardt, F. Lyman, and C. Spitzer, "Determination of free and conjugated triclosan-1 in blood by electron capture gas liquid chromatography-2," Journal of the American Oil Chemists' Society, vol. 52, no. 7, pp. 215-218, 1975.

[19] L. M. Weatherly and J. A. Gosse, "Triclosan exposure, transformation, and human health effects," Journal of Toxicology and Environmental Health Part B, Critical Reviews, vol. 20, no. 8, pp. 447-469, 2017. 
[20] Q. Wu, H. Shi, C. D. Adams, T. Timmons, and Y. Ma, "Oxidative removal of selected endocrine-disruptors and pharmaceuticals in drinking water treatment systems, and identification of degradation products of triclosan," Science of The Total Environment, vol. 439, pp. 18-25, 2012.

[21] C. Queckenberg, J. Meins, B. Wachall et al., "Absorption, pharmacokinetics, and safety of triclosan after dermal administration," Antimicrobial Agents and Chemotherapy, vol. 54, no. 1, pp. 570-572, 2010.

[22] G. Sandborgh-Englund, M. Adolfsson-Erici, G. Odham, and J. Ekstrand, "Pharmacokinetics of triclosan following oral ingestion in humans," Journal of Toxicology and Environmental Health Part A, vol. 69, no. 20, pp. 18611873, 2006.

[23] S. B. Levy, "Antibacterial household products: cause for concern," Emerging Infectious Diseases, vol. 7, Supplement 3, pp. 512-515, 2001.

[24] L. M. Weatherly, A. J. Nelson, J. Shim et al., "Antimicrobial agent triclosan disrupts mitochondrial structure, revealed by super-resolution microscopy, and inhibits mast cell signaling via calcium modulation," Toxicology and Applied Pharmacology, vol. 349, pp. 39-54, 2018.

[25] J. L. Fang, M. Vanlandingham, G. G. da Costa, and F. A. Beland, "Absorption and metabolism of triclosan after application to the skin of $\mathrm{B} 6 \mathrm{C} 3 \mathrm{~F} 1$ mice," Environmental Toxicology, vol. 31, no. 5, pp. 609-623, 2016.

[26] T. Moss, D. Howes, and F. M. Williams, "Percutaneous penetration and dermal metabolism of triclosan $\left(2,4,4^{\prime}\right.$ trichloro-2' -hydroxydiphenyl ether)," Food and Chemical Toxicology, vol. 38, no. 4, pp. 361-370, 2000.

[27] E. Franz and S. Weidner-Strahl, "The effectiveness of topical antibacterials in acne: a double-blind clinical study," The Journal of International Medical Research, vol. 6, no. 1, pp. $72-77,1978$.

[28] T. W. Lee, J. C. Kim, and S. J. Hwang, "Hydrogel patches containing triclosan for acne treatment," European Journal of Pharmaceutics and Biopharmaceutics, vol. 56, no. 3, pp. 407-412, 2003.

[29] P. Kalliomaki and K. Kuokkanen, "Comparative study on the efficacy and tolerance of the ointments CGP433 and GP41' 353 in the treatment of infectious dermatitis," Zeitschrift für Hautkrankheiten, vol. 54, no. 14, pp. 668-670, 1979.

[30] H. Weitgasser, C. Schindléry, and V. Macarol, "A comparative multicentre trial of halometasone/triclosan cream and betamethasone dipropionate/gentamicin sulphate cream in the treatment of infected acute eczematous dermatitis," The Journal of International Medical Research, vol. 11, Supplment 1, pp. 43-47, 1983.

[31] A. Aliaga, A. Castells, D. Kriznik et al., "An overview of two comparative multicentre trials with halometasone/triclosan cream in acute superficial bacterial skin infections," The Journal of International Medical Research, vol. 11, Supplement 1, pp. 53-57, 1983.

[32] L. Huber, "Role of Klion ointment in the treatment of crural ulcer," Therapia Hungarica, vol. 39, no. 3, pp. 148-150, 1991.

[33] P. Barkvoll and G. Rolla, "Triclosan protects the skin against dermatitis caused by sodium lauryl sulphate exposure," Journal of Clinical Periodontology, vol. 21, no. 10, pp. 717-719, 1994.

[34] A. Skaare, G. Eide, B. Herlofson, and P. Barkvoll, "The effect of toothpaste containing triclosan on oral mucosal desquamation. A model study," Journal of Clinical Periodontology, vol. 23, no. 12, pp. 1100-1103, 1996.

[35] V. Kjaerheim, P. Barkvoll, S. M. Waaler, and G. Rolla, "Triclosan inhibits histamine-induced inflammation in human skin," Journal of Clinical Periodontology, vol. 22, no. 6, pp. 423-426, 1995.

[36] P. Barkvoll and G. Rolla, "Triclosan reduces the clinical symptoms of the allergic patch test reaction (APR) elicited with $1 \%$ nickel sulphate in sensitised patients," Journal of Clinical Periodontology, vol. 22, no. 6, pp. 485-487, 1995.

[37] V. Kjaerheim, A. Roed, P. Brodin, and G. Rolla, "Effects of triclosan on the rat phrenic nerve-diaphragm preparation," Journal of Clinical Periodontology, vol. 22, no. 6, pp. 488493, 1995.

[38] F. L. Lyman and T. Furia, "Toxicology of 2, 4, 4'-trichloro-2'hydroxy-diphenyl ether," IMS, Industrial Medicine and Surgery, vol. 38, no. 2, pp. 64-71, 1969.

[39] F. L. Lyman and T. E. Furia, "Toxicology of 2,4,4' -trichloro2'-hydroxyphenyl ether," IMS, Industrial Medicine and Surgery, vol. 37, no. 7, p. 546, 1968.

[40] E. Arrhenius, L. Renberg, L. Johansson, and M. A. Zetterqvist, "Disturbance of microsomal detoxication mechanisms in liver by chlorophenol pesticides," Chemico-Biological Interactions, vol. 18, no. 1, pp. 35-46, 1977.

[41] A. Y. K. Chow, G. H. Hirsch, and H. S. Buttar, "Nephrotoxic and hepatotoxic effects of triclosan and chlorhexidine in rats," Toxicology and Applied Pharmacology, vol. 42, no. 1, pp. 1-10, 1977.

[42] L. B. Russell and C. S. Montgomery, "Use of the mouse spot test to investigate the mutagenic potential of triclosan (Irgasan DP300)," Mutation Research, vol. 79, no. 1, pp. 7-12, 1980.

[43] T. L. Miller, D. J. Lorusso, and M. L. Deinzer, "The acute toxicity of nonachloropredioxin and 3- and 4hydroxynonachlorodiphenyl ether in mice," Journal of Toxicology and Environmental Health, vol. 10, no. 4-5, pp. 699-707, 1982.

[44] T. L. Miller, D. J. Lorusso, M. L. Walsh, and M. L. Deinzer, "The acute toxicity of penta-, hexa-, and heptachlorohydroxydiphenyl ethers in mice," Journal of Toxicology and Environmental Health, vol. 12, no. 2-3, pp. 245-253, 1983.

[45] J. Roed-Petersen, G. Auken, and N. Hjorth, "Contact sensitivity to Irgasan DP 300," Contact Dermatitis, vol. 1, no. 5, pp. 293-294, 1975.

[46] B. Steinkjer and L. R. Braathen, "Contact dermatitis from triclosan (Irgasan DP 300)," Contact Dermatitis, vol. 18, no. 4, pp. 243-244, 1988.

[47] E. Storer, K. J. Koh, and L. Warren, "Severe contact dermatitis as a result of an antiseptic bath oil," The Australasian Journal of Dermatology, vol. 45, no. 1, pp. 73-75, 2004.

[48] S. Veronesi, S. M. P. de Padova, D. Vanni, and M. Melino, "Contact dermatitis to triclosan," Contact Dermatitis, vol. 15, no. 4, pp. 257-258, 1986.

[49] C. S. M. Wong and M. H. Beck, "Allergic contact dermatitis from triclosan in antibacterial handwashes," Contact Dermatitis, vol. 45, no. 5, p. 307, 2001.

[50] W. A. Vischer and J. Regös, "Antimicrobial spectrum of Triclosan, a broad-spectrum antimicrobial agent for topical application," Zentralblatt fur Bakteriologie, Parasitenkunde, Infektionskramkheiten und hygiene, Erste Abteilung Originale, Reihe A: Medizinische Mikrobiologie und Parasitologie, vol. 226, no. 3, pp. 376-389, 1974. 
[51] P. Gilbert and A. J. McBain, "Literature-based evaluation of the potential risks associated with impregnation of medical devices and implants with triclosan," Surgical Infections, vol. 3, Supplement 1, pp. S55-S63, 2002.

[52] R. J. Heath, J. Li, G. E. Roland, and C. O. Rock, "Inhibition of the Staphylococcus aureus NADPH-dependent enoyl-acyl carrier protein reductase by triclosan and hexachlorophene," The Journal of Biological Chemistry, vol. 275, no. 7, pp. 46544659, 2000.

[53] J. C. Betts, A. McLaren, M. G. Lennon et al., "Signature gene expression profiles discriminate between isoniazid-, thiolactomycin-, and triclosan-treated Mycobacterium tuberculosis," Antimicrobial Agents and Chemotherapy, vol. 47, no. 9, pp. 2903-2913, 2003.

[54] V. B. Srinivasan, B. B. Singh, N. Priyadarshi, N. K. Chauhan, and G. Rajamohan, "Role of novel multidrug efflux pump involved in drug resistance in Klebsiella pneumoniae," PLoS One, vol. 9, no. 5, article e96288, 2014.

[55] N. Gou, S. Yuan, J. Lan, C. Gao, A. N. Alshawabkeh, and A. Z. $\mathrm{Gu}$, "A quantitative toxicogenomics assay reveals the evolution and nature of toxicity during the transformation of environmental pollutants," Environmental Science \& Technology, vol. 48, no. 15 , pp. 8855-8863, 2014.

[56] J. Lu, M. Jin, S. H. Nguyen et al., "Non-antibiotic antimicrobial triclosan induces multiple antibiotic resistance through genetic mutation," Environment International, vol. 118, pp. 257-265, 2018.

[57] B. F. G. Pycke, G. Vanermen, P. Monsieurs et al., "Toxicogenomic response of Rhodospirillum rubrum $\mathrm{S} 1 \mathrm{H}$ to the micropollutant triclosan," Applied and Environmental Microbiology, vol. 76, no. 11, pp. 3503-3513, 2010.

[58] L. M. McMurry, M. Oethinger, and S. B. Levy, "Overexpression of marA, soxS, or acrAB produces resistance to triclosan in laboratory and clinical strains of Escherichia coli," FEMS Microbiology Letters, vol. 166, no. 2, pp. 305-309, 1998.

[59] P. Nuonming, S. Khemthong, T. Dokpikul, R. Sukchawalit, and S. Mongkolsuk, "Characterization and regulation of AcrABR, a RND-type multidrug efflux system, in Agrobacterium tumefaciens C58," Microbiological Research, vol. 214, pp. 146-155, 2018.

[60] T. L. Miller and M. L. Deinzer, "Effects of nonachloropredioxin and other hydroxychlorodiphenyl ethers on biological membranes," Journal of Toxicology and Environmental Health, vol. 6, no. 1, pp. 11-25, 1980.

[61] D. J. Lorusso, T. L. Miller, and M. L. Deinzer, "Effect of hydroxychlorodiphenyl ethers (chlorinated pre-and isopredioxins) on erythrocyte membrane adenosinetriphosphatase activity," Journal of Toxicology and Environmental Health, vol. 8, no. 1-2, pp. 215-223, 1981.

[62] J. Villalain, C. R. Mateo, F. J. Aranda, S. Shapiro, and V. Micol, "Membranotropic effects of the antibacterial agent Triclosan," Archives of Biochemistry and Biophysics, vol. 390, no. 1, pp. 128-136, 2001.

[63] J. Guillén, A. Bernabeu, S. Shapiro, and J. Villalaín, "Location and orientation of Triclosan in phospholipid model membranes," European Biophysics Journal, vol. 33, no. 5, pp. 448-453, 2004.

[64] L. Canesi, C. Ciacci, L. C. Lorusso et al., "Effects of Triclosan on Mytilus galloprovincialis hemocyte function and digestive gland enzyme activities: possible modes of action on non target organisms," Comparative Biochemistry and Physiology
Part C: Toxicology \& Pharmacology, vol. 145, no. 3, pp. 464472, 2007.

[65] V. Matozzo, A. Costa Devoti, and M. G. Marin, "Immunotoxic effects of triclosan in the clam Ruditapes philippinarum," Ecotoxicology, vol. 21, no. 1, pp. 66-74, 2012.

[66] D. S. Yoon, Y. Choi, D. S. Cha et al., "Triclosan disrupts SKN$1 / \mathrm{Nrf2}$-mediated oxidative stress response in C. elegans and human mesenchymal stem cells," Scientific Reports, vol. 7, no. 1, article 12592, 2017.

[67] E. Falisse, A. S. Voisin, and F. Silvestre, "Impacts of triclosan exposure on zebrafish early-life stage: toxicity and acclimation mechanisms," Aquatic Toxicology, vol. 189, pp. 97107, 2017.

[68] C. Riva, S. Cristoni, and A. Binelli, "Effects of triclosan in the freshwater mussel Dreissena polymorpha: a proteomic investigation," Aquatic Toxicology, vol. 118-119, pp. 6271, 2012.

[69] H. Babich and J. P. Babich, "Sodium lauryl sulfate and triclosan: in vitro cytotoxicity studies with gingival cells," Toxicology Letters, vol. 91, no. 3, pp. 189-196, 1997.

[70] H. L. Zuckerbraun, H. Babich, R. May, and M. C. Sinensky, "Triclosan: cytotoxicity, mode of action, and induction of apoptosis in human gingival cells in vitro," European Journal of Oral Sciences, vol. 106, no. 2, Part 1, pp. 628-636, 1998.

[71] E. Honkisz, D. Zieba-Przybylska, and A. K. Wojtowicz, "The effect of triclosan on hormone secretion and viability of human choriocarcinoma JEG-3 cells," Reproductive Toxicology, vol. 34, no. 3, pp. 385-392, 2012.

[72] T. Winitthana, S. Lawanprasert, and P. Chanvorachote, "Triclosan potentiates epithelial-to-mesenchymal transition in anoikis-resistant human lung cancer cells," PLoS One, vol. 9, no. 10, article e110851, 2014.

[73] Y. S. Kim, H. W. Seo, M. H. Lee, D. K. Kim, H. Jeon, and D. S. Cha, "Protocatechuic acid extends lifespan and increases stress resistance in Caenorhabditis elegans," Archives of Pharmacal Research, vol. 37, no. 2, pp. 245-252, 2014.

[74] H. R. Lee, K. A. Hwang, K. H. Nam, H. C. Kim, and K. C. Choi, "Progression of breast cancer cells was enhanced by endocrine-disrupting chemicals, triclosan and octylphenol, via an estrogen receptor-dependent signaling pathway in cellular and mouse xenograft models," Chemical Research in Toxicology, vol. 27, no. 5, pp. 834-842, 2014.

[75] S. H. Kim, K. A. Hwang, and K. C. Choi, "Treatment with kaempferol suppresses breast cancer cell growth caused by estrogen and triclosan in cellular and xenograft breast cancer models," The Journal of Nutritional Biochemistry, vol. 28, pp. 70-82, 2016.

[76] G. A. Lee, K. C. Choi, and K. A. Hwang, "Treatment with phytoestrogens reversed triclosan and bisphenol A-induced anti-apoptosis in breast cancer cells," Biomolecules \& Therapeutics, vol. 26, no. 5, pp. 503-511, 2018.

[77] S. H. Kim, K. A. Hwang, S. M. Shim, and K. C. Choi, "Growth and migration of LNCaP prostate cancer cells are promoted by triclosan and benzophenone-1 via an androgen receptor signaling pathway," Environmental Toxicology and Pharmacology, vol. 39, no. 2, pp. 568-576, 2015.

[78] N. Zhang, W. Wang, W. Li et al., "Inhibition of 11 $\beta$-HSD2 expression by triclosan via induction of apoptosis in human placental syncytiotrophoblasts," The Journal of Clinical Endocrinology and Metabolism, vol. 100, no. 4, pp. E542E549, 2015. 
[79] B. K. Park, E. L. T. Gonzales, S. M. Yang, M. Bang, C. S. Choi, and C. Y. Shin, "Effects of triclosan on neural stem cell viability and survival," Biomolecules \& Therapeutics, vol. 24, no. 1, pp. 99-107, 2016.

[80] K. A. Szychowski, A. M. Sitarz, and A. K. Wojtowicz, "Triclosan induces Fas receptor-dependent apoptosis in mouse neocortical neurons in vitro," Neuroscience, vol. 284, pp. 192-201, 2015.

[81] K. A. Szychowski, A. Wnuk, M. Kajta, and A. K. Wojtowicz, "Triclosan activates aryl hydrocarbon receptor (AhR)dependent apoptosis and affects Cyp1a1 and Cyp1b1 expression in mouse neocortical neurons," Environmental Research, vol. 151, pp. 106-114, 2016.

[82] K. A. Szychowski, A. Wnuk, J. Rzemieniec, M. Kajta, T. Leszczyńska, and A. K. Wójtowicz, "Triclosan-evoked neurotoxicity involves NMDAR subunits with the specific role of GluN2A in caspase-3-dependent apoptosis," Molecular Neurobiology, vol. 56, no. 1, pp. 1-12, 2019.

[83] J. T. Kwon, Y. S. Yang, M. S. Kang et al., "Pulmonary toxicity screening of triclosan in rats after intratracheal instillation," The Journal of Toxicological Sciences, vol. 38, no. 3, pp. 471475, 2013.

[84] Y. Wu, F. A. Beland, S. Chen, and J. L. Fang, "Extracellular signal-regulated kinases $1 / 2$ and Akt contribute to triclosanstimulated proliferation of JB6 Cl 41-5a cells," Archives of Toxicology, vol. 89, no. 8, pp. 1297-1311, 2015.

[85] X. Chen, B. Xu, X. Han et al., "The effects of triclosan on pluripotency factors and development of mouse embryonic stem cells and zebrafish," Archives of Toxicology, vol. 89, no. 4, pp. 635-646, 2015.

[86] J. Kim, H. Oh, B. Ryu et al., "Triclosan affects axon formation in the neural development stages of zebrafish embryos (Danio rerio)," Environmental Pollution, vol. 236, pp. 304$312,2018$.

[87] J. Liu, L. Sun, H. Zhang et al., "Response mechanisms to joint exposure of triclosan and its chlorinated derivatives on zebrafish (Danio rerio) behavior," Chemosphere, vol. 193, pp. 820832, 2018.

[88] A. Binelli, D. Cogni, M. Parolini, C. Riva, and A. Provini, "Cytotoxic and genotoxic effects of in vitro exposure to triclosan and trimethoprim on zebra mussel (Dreissena polymorpha) hemocytes," Comparative Biochemistry and Physiology Part C: Toxicology \& Pharmacology, vol. 150, no. 1, pp. 5056, 2009.

[89] A. Binelli, D. Cogni, M. Parolini, C. Riva, and A. Provini, "In vivo experiments for the evaluation of genotoxic and cytotoxic effects of Triclosan in Zebra mussel hemocytes," Aquatic Toxicology, vol. 91, no. 3, pp. 238-244, 2009.

[90] M. Gonzalez-Pleiter, C. Rioboo, M. Reguera et al., "Calcium mediates the cellular response of Chlamydomonas reinhardtii to the emerging aquatic pollutant Triclosan," Aquatic Toxicology, vol. 186, pp. 50-66, 2017.

[91] E. Movahed, G. M. Y. Tan, K. Munusamy et al., "Triclosan demonstrates synergic effect with amphotericin B and fluconazole and induces apoptosis-like cell death in Cryptococcus neoformans," Frontiers in Microbiology, vol. 7, p. 360, 2016.

[92] D. J. Watkins, K. K. Ferguson, L. V. Anzalota Del Toro, A. N. Alshawabkeh, J. F. Cordero, and J. D. Meeker, "Associations between urinary phenol and paraben concentrations and markers of oxidative stress and inflammation among pregnant women in Puerto Rico," International Journal of
Hygiene and Environmental Health, vol. 218, no. 2, pp. 212-219, 2015.

[93] Y. Lv, C. Rui, Y. Dai et al., "Exposure of children to BPA through dust and the association of urinary BPA and triclosan with oxidative stress in Guangzhou, China," Environmental Science: Processes \& Impacts, vol. 18, no. 12, pp. 1492-1499, 2016.

[94] B. A. Rocha, A. G. Asimakopoulos, M. Honda et al., "Advanced data mining approaches in the assessment of urinary concentrations of bisphenols, chlorophenols, parabens and benzophenones in Brazilian children and their association to DNA damage," Environment International, vol. 116, pp. 269-277, 2018.

[95] A. P. Iyer, J. Xue, M. Honda et al., "Urinary levels of triclosan and triclocarban in several Asian countries, Greece and the USA: association with oxidative stress," Environmental Research, vol. 160, pp. 91-96, 2018.

[96] B. Bukowska, P. Wieteska, M. Kwiatkowska, P. Sicinska, and J. Michalowicz, "Evaluation of the effect of 2,4-dichlorophenol on oxidative parameters and viability of human blood mononuclear cells (in vitro)," Human \& Experimental Toxicology, vol. 35, no. 7, pp. 775-784, 2016.

[97] P. Zhang, M. Yang, L. Zeng, and C. Liu, "P38/TRHrdependent regulation of TPO in thyroid cells contributes to the hypothyroidism of triclosan-treated rats," Cellular Physiology and Biochemistry, vol. 45, no. 4, pp. 1303-1315, 2018.

[98] S. Vandhana, K. Coral, U. Jayanthi, P. R. Deepa, and S. Krishnakumar, "Biochemical changes accompanying apoptotic cell death in retinoblastoma cancer cells treated with lipogenic enzyme inhibitors," Biochimica et Biophysica Acta (BBA) - Molecular and Cell Biology of Lipids, vol. 1831, no. 9, pp. 1458-1466, 2013.

[99] M. Battino, M. S. Ferreiro, D. Fattorini, and P. Bullon, "In vitro antioxidant activities of mouthrinses and their components," Journal of Clinical Periodontology, vol. 29, no. 5, pp. 462-467, 2002.

[100] C. Ajao, M. A. Andersson, V. V. Teplova et al., "Mitochondrial toxicity of triclosan on mammalian cells," Toxicology Reports, vol. 2, pp. 624-637, 2015.

[101] L. M. Weatherly, J. Shim, H. N. Hashmi, R. H. Kennedy, S. T. Hess, and J. A. Gosse, "Antimicrobial agent triclosan is a proton ionophore uncoupler of mitochondria in living rat and human mast cells and in primary human keratinocytes," Journal of Applied Toxicology, vol. 36, no. 6, pp. 777789, 2016

[102] I. Tamura, Y. Kanbara, M. Saito et al., "Triclosan, an antibacterial agent, increases intracellular $\mathrm{Zn}^{2+}$ concentration in rat thymocytes: its relation to oxidative stress," Chemosphere, vol. 86, no. 1, pp. 70-75, 2012.

[103] M. F. Yueh, K. Taniguchi, S. Chen et al., "The commonly used antimicrobial additive triclosan is a liver tumor promoter," Proceedings of the National Academy of Sciences of the United States of America, vol. 111, no. 48, pp. 17200-17205, 2014.

[104] M. A. Riad, M. M. Abd-Rabo, S. A. Abd El Aziz, A. M. El Behairy, and M. M. Badawy, "Reproductive toxic impact of subchronic treatment with combined butylparaben and triclosan in weanling male rats," Journal of Biochemical and Molecular Toxicology, vol. 32, no. 3, article e22037, 2018.

[105] A. T. Mohammed, A. A.-R. Mohamed, and H. Ali, "Pulmonary apoptotic and oxidative damaging effects of Triclosan alone or in combination with fluoride in Sprague Dawley rats," Acta Histochemica, vol. 119, no. 4, pp. 357-363, 2017. 
[106] Z. Wang, X. Li, and J. E. Klaunig, "Investigation of the mechanism of triclosan induced mouse liver tumors," Regulatory Toxicology and Pharmacology, vol. 86, pp. 137-147, 2017.

[107] K. A. Lenz, C. Pattison, and H. Ma, “Triclosan (TCS) and triclocarban (TCC) induce systemic toxic effects in a model organism the nematode Caenorhabditis elegans," Environmental Pollution, vol. 231, Part 1, pp. 462-470, 2017.

[108] D. Lin, Q. Zhou, X. Xie, and Y. Liu, "Potential biochemical and genetic toxicity of triclosan as an emerging pollutant on earthworms (Eisenia fetida)," Chemosphere, vol. 81, no. 10, pp. 1328-1333, 2010.

[109] D. Lin, X. Xie, Q. Zhou, and Y. Liu, "Biochemical and genotoxic effect of triclosan on earthworms (Eisenia fetida) using contact and soil tests," Environmental Toxicology, vol. 27, no. 7, pp. 385-392, 2012.

[110] X. Wang, Z. Liu, W. Wang et al., "Assessment of toxic effects of triclosan on the terrestrial snail (Achatina fulica)," Chemosphere, vol. 108, pp. 225-230, 2014.

[111] Z. Zhou, J. Yang, and K. M. Chan, "Toxic effects of triclosan on a zebrafish (Danio rerio) liver cell line, ZFL," Aquatic Toxicology, vol. 191, pp. 175-188, 2017.

[112] Y. Peng, Y. Luo, X. P. Nie, W. Liao, Y. F. Yang, and G. G. Ying, "Toxic effects of triclosan on the detoxification system and breeding of Daphnia magna," Ecotoxicology, vol. 22, no. 9, pp. 1384-1394, 2013.

[113] V. Kovacevic, A. J. Simpson, and M. J. Simpson, “(1)H NMRbased metabolomics of Daphnia magna responses after sublethal exposure to triclosan, carbamazepine and ibuprofen," Comparative Biochemistry and Physiology Part D, Genomics \& Proteomics, vol. 19, pp. 199-210, 2016.

[114] H. I. Falfushynska, L. L. Gnatyshyna, O. Y. Osadchuk et al., "Diversity of the molecular responses to separate wastewater effluents in freshwater mussels," Comparative Biochemistry and Physiology Part C: Toxicology \& Pharmacology, vol. 164, pp. 51-58, 2014.

[115] J. C. Park, J. Han, M. C. Lee, J. S. Seo, and J. S. Lee, "Effects of triclosan (TCS) on fecundity, the antioxidant system, and oxidative stress-mediated gene expression in the copepod Tigriopus japonicus," Aquatic Toxicology, vol. 189, pp. 1624, 2017.

[116] P. Ku, X. Wu, X. Nie et al., "Effects of triclosan on the detoxification system in the yellow catfish (Pelteobagrus fulvidraco): expressions of CYP and GST genes and corresponding enzyme activity in phase I, II and antioxidant system," Comparative Biochemistry and Physiology Part C: Toxicology \& Pharmacology, vol. 166, pp. 105-114, 2014.

[117] P. Banerjee, T. K. Dey, S. Sarkar, S. Swarnakar, A. Mukhopadhyay, and S. Ghosh, "Treatment of cosmetic effluent in different configurations of ceramic UF membrane based bioreactor: toxicity evaluation of the untreated and treated wastewater using catfish (Heteropneustes fossilis)," Chemosphere, vol. 146, pp. 133-144, 2016.

[118] F. Wang, R. Xu, F. Zheng, and H. Liu, "Effects of triclosan on acute toxicity, genetic toxicity and oxidative stress in goldfish (Carassius auratus)," Experimental Animals, vol. 67, no. 2, pp. 219-227, 2018.

[119] C. Li, R. Qu, J. Chen et al., "The pH-dependent toxicity of triclosan to five aquatic organisms (Daphnia magna, Photobacterium phosphoreum, Danio rerio, Limnodrilus hoffmeisteri, and Carassius auratus)," Environmental Science and Pollution Research International, vol. 25, no. 10, pp. 96369646, 2018.
[120] J. Han, E. J. Won, U. K. Hwang, I. C. Kim, J. H. Yim, and J. S. Lee, "Triclosan (TCS) and Triclocarban (TCC) cause lifespan reduction and reproductive impairment through oxidative stress-mediated expression of the defensome in the monogonont rotifer (Brachionus koreanus)," Comparative Biochemistry and Physiology Part C: Toxicology \& Pharmacology, vol. 185-186, pp. 131-137, 2016.

[121] L. Chai, A. Chen, P. Luo, H. Zhao, and H. Wang, "Histopathological changes and lipid metabolism in the liver of Bufo gargarizans tadpoles exposed to Triclosan," Chemosphere, vol. 182, pp. 255-266, 2017.

[122] D. Martins, M. S. Monteiro, A. M. V. M. Soares, and C. Quintaneiro, "Effects of 4-MBC and triclosan in embryos of the frog Pelophylax perezi," Chemosphere, vol. 178, pp. 325-332, 2017.

[123] M. Sendra, M. G. Pintado-Herrera, G. V. Aguirre-Martinez et al., "Are the TiO2 NPs a "Trojan horse" for personal care products (PCPs) in the clam Ruditapes philippinarum?," Chemosphere, vol. 185, pp. 192-204, 2017.

[124] E. Capkin, T. Ozcelep, S. Kayis, and I. Altinok, "Antimicrobial agents, triclosan, chloroxylenol, methylisothiazolinone and borax, used in cleaning had genotoxic and histopathologic effects on rainbow trout," Chemosphere, vol. 182, pp. 720-729, 2017.

[125] A. C. Almeida, T. Gomes, K. Langford, K. V. Thomas, and K. E. Tollefsen, "Oxidative stress in the algae Chlamydomonas reinhardtii exposed to biocides," Aquatic Toxicology, vol. 189, pp. 50-59, 2017.

[126] C. G. Pan, F. J. Peng, W. J. Shi, L. X. Hu, X. D. Wei, and G. G. Ying, "Triclosan-induced transcriptional and biochemical alterations in the freshwater green algae Chlamydomonas reinhardtii," Ecotoxicology and Environmental Safety, vol. 148, pp. 393-401, 2018.

[127] J. Hurtado-Gallego, K. Martin-Betancor, I. Rodea-Palomares, F. Leganes, R. Rosal, and F. Fernandez-Pinas, "Two novel cyanobacterial bioluminescent whole-cell bioreporters based on superoxide dismutases MnSod and FeSod to detect superoxide anion," Chemosphere, vol. 201, pp. 772-779, 2018.

[128] O. Culic, V. Erakovic, and M. J. Parnham, "Anti-inflammatory effects of macrolide antibiotics," European Journal of Pharmacology, vol. 429, no. 1-3, pp. 209-229, 2001.

[129] Y. Iino, M. Toriyama, Y. Natori, K. Kudo, and A. Yuo, "Erythromycin inhibition of lipopolysaccharide-stimulated tumor necrosis factor alpha production by human monocytes in vitro," The Annals of Otology, Rhinology \& Laryngology. Supplement, vol. 101, 10 Supplement, pp. 16-20, 1992.

[130] O. M. Korzeniowski, "Effects of antibiotics on the mammalian immune system," Infectious Disease Clinics of North America, vol. 3, no. 3, pp. 469-478, 1989.

[131] S. M. Uriarte, R. E. Molestina, R. D. Miller et al., "Effects of fluoroquinolones on the migration of human phagocytes through Chlamydia pneumoniae-infected and tumor necrosis factor alpha-stimulated endothelial cells," Antimicrobial Agents and Chemotherapy, vol. 48, no. 7, pp. 25382543, 2004.

[132] B. Van Vlem, R. Vanholder, P. De Paepe, S. Ringoir, and D. Vogelaers, "Immunomodulating effects of antibiotics: literature review," Infection, vol. 24, no. 4, pp. 275-291, 1996.

[133] A. Gaffar, D. Scherl, J. Afflitto, and E. J. Coleman, "The effect of triclosan on mediators of gingival inflammation," Journal of Clinical Periodontology, vol. 22, no. 6, pp. 480484, 1995. 
[134] T. Modéer, A. Bengisson, and G. Rölla, “Triclosan reduces prostaglandin biosynthesis in human gingival fibroblasts challenged with interleukin-1 in vitro," Journal of Clinical Periodontology, vol. 23, no. 10, pp. 927-933, 1996.

[135] A. B. Skaare, G. Rolla, and P. Barkvoll, "The influence of triclosan, zinc or propylene glycol on oral mucosa exposed to sodium lauryl sulphate," European Journal of Oral Sciences, vol. 105, no. 5, Part 2, pp. 527-533, 1997.

[136] T. M. Hernandez-Richter, M. W. Wichmann, W. Schrodl, M. K. Angele, K. Heinritzi, and F. W. Schildberg, "The acute phase response following implantation of triclosan-bonded vascular prostheses," Clinical and Experimental Medicine, vol. 1, no. 1, pp. 35-41, 2001.

[137] S. Kumar, "Little difference between triclosan and stannous fluoride dentifrices on gingival inflammation," EvidenceBased Dentistry, vol. 16, no. 1, pp. 13-14, 2015.

[138] D. K. Suresh, K. L. Vandana, and D. S. Mehta, "Intracrevicular application of $0.3 \%$ Flurbiprofen gel and $0.3 \%$ Triclosan gel as anti inflammatory agent. A comparative clinical study," Indian Journal of Dental Research, vol. 12, no. 2, pp. 105-112, 2001.

[139] F. V. Ribeiro, M. Z. Casati, R. C. Casarin et al., "Impact of a triclosan-containing toothpaste during the progression of experimental peri-implant mucositis: clinical parameters and local pattern of osteo-immunoinflammatory mediators in peri-implant fluid," Journal of Periodontology, vol. 89, no. 2, pp. 203-212, 2018.

[140] M. Mustafa, M. Bakhiet, B. Wondimu, and T. Modeer, "Effect of triclosan on interferon-gamma production and major histocompatibility complex class II expression in human gingival fibroblasts," Journal of Clinical Periodontology, vol. 27 , no. 10 , pp. 733-737, 2000.

[141] M. Mustafa, B. Wondimu, M. Ibrahim, and T. Modeer, "Effect of triclosan on interleukin-1beta production in human gingival fibroblasts challenged with tumor necrosis factor alpha," European Journal of Oral Sciences, vol. 106, no. 2, Part 1, pp. 637-643, 1998.

[142] M. Mustafa, B. Wondimu, T. Yucel-Lindberg, A. T. KatsHallstrom, A. S. Jonsson, and T. Modeer, "Triclosan reduces microsomal prostaglandin E synthase-1 expression in human gingival fibroblasts," Journal of Clinical Periodontology, vol. 32, no. 1, pp. 6-11, 2005.

[143] M. Mustafa, B. Wondimu, K. Hultenby, T. Yucel-Lindberg, and T. Modeer, "Uptake, distribution and release of 14Ctriclosan in human gingival fibroblasts," Journal of Pharmaceutical Sciences, vol. 92, no. 8, pp. 1648-1653, 2003.

[144] M. A. Wallet, N. L. Calderon, T. R. Alonso et al., "Triclosan alters antimicrobial and inflammatory responses of epithelial cells," Oral Diseases, vol. 19, no. 3, pp. 296-302, 2013.

[145] K. G. Neiva, N. L. Calderon, T. R. Alonso, F. Panagakos, and S. M. Wallet, "Type 1 diabetes-associated TLR responsiveness of oral epithelial cells," Journal of Dental Research, vol. 93, no. 2, pp. 169-174, 2014.

[146] N. B. Marshall, E. Lukomska, A. P. Nayak, C. M. Long, J. M. Hettick, and S. E. Anderson, "Topical application of the antimicrobial chemical triclosan induces immunomodulatory responses through the S100A8/A9-TLR4 pathway," Journal of Immunotoxicology, vol. 14, no. 1, pp. 50-59, 2017.

[147] V. M. Barnes, T. Xu, E. Shimizu et al., "Triclosan blocks MMP-13 expression in hormone-stimulated osteoblasts," Journal of Periodontology, vol. 84, no. 11, pp. 1-9, 2013.
[148] B. A. Pancer, D. Kott, J. V. Sugai et al., "Effects of triclosan on host response and microbial biomarkers during experimental gingivitis," Journal of Clinical Periodontology, vol. 43, no. 5, pp. 435-444, 2016.

[149] M. P. Cullinan, J. E. Palmer, M. J. Faddy et al., "The influence of triclosan on biomarkers of cardiovascular risk in patients in the Cardiovascular and Periodontal Study (CAPS): a randomized controlled trial," Journal of Periodontology, vol. 86, no. 7, pp. 847-855, 2015.

[150] S. Hessam, M. Sand, N. M. Meier, T. Gambichler, L. Scholl, and F. G. Bechara, "Combination of oral zinc gluconate and topical triclosan: an anti-inflammatory treatment modality for initial hidradenitis suppurativa," Journal of Dermatological Science, vol. 84, no. 2, pp. 197-202, 2016.

[151] P. A. Cadieux, B. H. Chew, B. E. Knudsen et al., "Triclosan loaded ureteral stents decrease proteus mirabilis 296 infection in a rabbit urinary tract infection model," The Journal of Urology, vol. 175, no. 6, pp. 2331-2335, 2006.

[152] C. N. Elwood, B. H. Chew, S. Seney, J. Jass, J. D. Denstedt, and P. A. Cadieux, "Triclosan inhibits uropathogenic Escherichia coli-stimulated tumor necrosis factor-alpha secretion in T24 bladder cells in vitro," Journal of Endourology, vol. 21, no. 10, pp. 1217-1222, 2007.

[153] S. P. Barros, S. Wirojchanasak, D. A. Barrow, F. S. Panagakos, W. Devizio, and S. Offenbacher, "Triclosan inhibition of acute and chronic inflammatory gene pathways," Journal of Clinical Periodontology, vol. 37, no. 5, pp. 412-418, 2010.

[154] F. Udoji, T. Martin, R. Etherton, and M. M. Whalen, "Immunosuppressive effects of triclosan, nonylphenol, and DDT on human natural killer cells in vitro," Journal of Immunotoxicology, vol. 7, no. 3, pp. 205-212, 2010.

[155] L. Pavez, N. Tobar, C. Chacon et al., "Chitosan-triclosan particles modulate inflammatory signaling in gingival fibroblasts," Journal of Periodontal Research, vol. 53, no. 2, pp. 232-239, 2018.

[156] S. Sharma, T. N. C. Ramya, A. Surolia, and N. Surolia, "Triclosan as a systemic antibacterial agent in a mouse model of acute bacterial challenge," Antimicrobial Agents and Chemotherapy, vol. 47, no. 12, pp. 3859-3866, 2003.

[157] H. Yang, W. Wang, K. A. Romano et al., "A common antimicrobial additive increases colonic inflammation and colitisassociated colon tumorigenesis in mice," Science Translational Medicine, vol. 10, no. 443, article eaan4116, 2018.

[158] A. Kanetoshi, E. Katsura, H. Ogawa, T. Ohyama, H. Kaneshima, and T. Miura, "Acute toxicity, percutaneous absorption and effects on hepatic mixed function oxidase activities of 2,4,4' -trichloro-2' -hydroxydiphenyl ether (Irgasan DP300) and its chlorinated derivatives," Archives of Environmental Contamination and Toxicology, vol. 23, no. 1, pp. 91-98, 1992.

[159] H. Ma, L. Zheng, Y. Li et al., "Triclosan reduces the levels of global DNA methylation in HepG2 cells," Chemosphere, vol. 90, no. 3, pp. 1023-1029, 2013.

[160] F. Rodrigues, M. Lehmann, V. S. do Amaral, M. L. Reguly, and H. H. R. de Andrade, "Genotoxicity of three mouthwash products, Cepacol ${ }^{\circledR}$, Periogard ${ }^{\circledR}$, and Plax ${ }^{\circledR}$, in the Drosophila wing-spot test," Environmental and Molecular Mutagenesis, vol. 48, no. 8, pp. 644-649, 2007.

[161] F. Chevillot, M. Guyot, M. Desrosiers et al., "Accumulation and sublethal effects of triclosan and its transformation product methyl-triclosan in the earthworm Eisenia andrei exposed to environmental concentrations in an artificial soil," 
Environmental Toxicology and Chemistry, vol. 37, no. 7, pp. 1940-1948, 2018.

[162] P. Martinez-Paz, M. Morales, J. L. Martinez-Guitarte, and G. Morcillo, "Genotoxic effects of environmental endocrine disruptors on the aquatic insect Chironomus riparius evaluated using the comet assay," Mutation Research, vol. 758, no. 1-2, pp. 41-47, 2013.

[163] A. R. R. Silva, D. N. Cardoso, A. Cruz et al., "Ecotoxicity and genotoxicity of a binary combination of triclosan and carbendazim to Daphnia magna," Ecotoxicology and Environmental Safety, vol. 115, pp. 279-290, 2015.

[164] X. Xu, Y. Lu, D. Zhang et al., "Toxic assessment of triclosan and triclocarban on Artemia salina," Bulletin of Environmental Contamination and Toxicology, vol. 95, no. 6, pp. 728733, 2015.

[165] L. Gao, T. Yuan, P. Cheng et al., "Effects of triclosan and triclocarban on the growth inhibition, cell viability, genotoxicity and multixenobiotic resistance responses of Tetrahymena thermophila," Chemosphere, vol. 139, pp. 434-440, 2015.

[166] O. Herrero, J. M. Perez Martin, P. Fernandez Freire, L. Carvajal Lopez, A. Peropadre, and M. J. Hazen, "Toxicological evaluation of three contaminants of emerging concern by use of the Allium cepa test," Mutation Research, vol. 743, no. 1-2, pp. 20-24, 2012.

[167] T. Y. Doktorova, G. Ates, M. Vinken, T. Vanhaecke, and V. Rogiers, "Way forward in case of a false positive in vitro genotoxicity result for a cosmetic substance?," Toxicology In Vitro, vol. 28, no. 1, pp. 54-59, 2014.

[168] K. Z. Sanidad, H. Xiao, and G. Zhang, "Triclosan, a common antimicrobial ingredient, on gut microbiota and gut health," Gut Microbes, pp. 1-4, 2018.

[169] H. N. Bhargava and P. A. Leonard, "Triclosan: applications and safety," American Journal of Infection Control, vol. 24, no. 3, pp. 209-218, 1996.

[170] R. U. Halden, A. E. Lindeman, A. E. Aiello et al., "The Florence statement on triclosan and triclocarban," Environmental Health Perspectives, vol. 125, no. 6, article 064501, 2017.

[171] I. J. Uings and S. N. Farrow, "Cell receptors and cell signalling," Molecular Pathology, vol. 53, no. 6, pp. 295-299, 2000.

[172] G. A. Lee, K. A. Hwang, and K. C. Choi, "Inhibitory effects of 3,3'-diindolylmethane on epithelial-mesenchymal transition induced by endocrine disrupting chemicals in cellular and xenograft mouse models of breast cancer," Food and Chemical Toxicology, vol. 109, Part 1, pp. 284-295, 2017.

[173] H. Huang, G. Du, W. Zhang et al., "The in vitro estrogenic activities of triclosan and triclocarban," Journal of Applied Toxicology, vol. 34, no. 9, pp. 1060-1067, 2014.

[174] N. D. Henry and P. A. Fair, "Comparison of in vitro cytotoxicity, estrogenicity and anti-estrogenicity of triclosan, perfluorooctane sulfonate and perfluorooctanoic acid," Journal of Applied Toxicology, vol. 33, no. 4, pp. 265-272, 2013.

[175] T. E. Stoker, E. K. Gibson, and L. M. Zorrilla, "Triclosan exposure modulates estrogen-dependent responses in the female Wistar rat," Toxicological Sciences, vol. 117, no. 1, pp. 45-53, 2010.

[176] G. W. Louis, D. R. Hallinger, and T. E. Stoker, "The effect of triclosan on the uterotrophic response to extended doses of ethinyl estradiol in the weanling rat," Reproductive Toxicology, vol. 36, pp. 71-77, 2013.

[177] M. O. James, W. Li, D. P. Summerlot, L. Rowland-Faux, and C. E. Wood, "Triclosan is a potent inhibitor of estradiol and estrone sulfonation in sheep placenta," Environment International, vol. 36, no. 8, pp. 942-949, 2010.

[178] E. M. Jung, B. S. An, K. C. Choi, and E. B. Jeung, "Potential estrogenic activity of triclosan in the uterus of immature rats and rat pituitary GH3 cells," Toxicology Letters, vol. 208, no. 2, pp. 142-148, 2012.

[179] H. Serra, F. Brion, J. M. Porcher, H. Budzinski, and S. AitAissa, "Triclosan lacks anti-estrogenic effects in zebrafish cells but modulates estrogen response in zebrafish embryos," International Journal of Molecular Sciences, vol. 19, no. 4, p. $1175,2018$.

[180] S. Miyagawa, A. Lange, I. Hirakawa et al., "Differing species responsiveness of estrogenic contaminants in fish is conferred by the ligand binding domain of the estrogen receptor," Environmental Science \& Technology, vol. 48, no. 9, pp. 5254-5263, 2014.

[181] J. Chen, K. C. Ahn, N. A. Gee, S. J. Gee, B. D. Hammock, and B. L. Lasley, "Antiandrogenic properties of parabens and other phenolic containing small molecules in personal care products," Toxicology and Applied Pharmacology, vol. 221, no. 3, pp. 278-284, 2007.

[182] V. Christen, P. Crettaz, A. Oberli-Schrammli, and K. Fent, "Some flame retardants and the antimicrobials triclosan and triclocarban enhance the androgenic activity in vitro," Chemosphere, vol. 81, no. 10, pp. 1245-1252, 2010.

[183] K. C. Ahn, B. Zhao, J. Chen et al., "In vitro biologic activities of the antimicrobials triclocarban, its analogs, and triclosan in bioassay screens: receptor-based bioassay screens," Environmental Health Perspectives, vol. 116, no. 9, pp. 12031210, 2008.

[184] R. H. Gee, A. Charles, N. Taylor, and P. D. Darbre, "Oestrogenic and androgenic activity of triclosan in breast cancer cells," Journal of Applied Toxicology, vol. 28, no. 1, pp. 78-91, 2008.

[185] A. L. Forgacs, Q. Ding, R. G. Jaremba, I. T. Huhtaniemi, N. A. Rahman, and T. R. Zacharewski, "BLTK1 murine Leydig cells: a novel steroidogenic model for evaluating the effects of reproductive and developmental toxicants," Toxicological Sciences, vol. 127, no. 2, pp. 391-402, 2012.

[186] W. T. Farmer, G. W. Louis, A. R. Buckalew, D. R. Hallinger, and T. E. Stoker, "Evaluation of triclosan in the Hershberger and H295R steroidogenesis assays," Toxicology Letters, vol. 291, pp. 194-199, 2018.

[187] Y. Wu, Q. Wu, F. A. Beland, P. Ge, M. G. Manjanatha, and J. L. Fang, "Differential effects of triclosan on the activation of mouse and human peroxisome proliferator-activated receptor alpha," Toxicology Letters, vol. 231, no. 1, pp. 1728, 2014.

[188] P. Xia, X. Zhang, Y. Xie, M. Guan, D. L. Villeneuve, and $\mathrm{H}$. Yu, "Functional toxicogenomic assessment of triclosan in human HepG2 cells using genome-wide CRISPR-Cas9 screening," Environmental Science \& Technology, vol. 50, no. 19, pp. 10682-10692, 2016.

[189] D. E. Haggard, P. D. Noyes, K. M. Waters, and R. L. Tanguay, "Phenotypically anchored transcriptome profiling of developmental exposure to the antimicrobial agent, triclosan, reveals hepatotoxicity in embryonic zebrafish," Toxicology and Applied Pharmacology, vol. 308, pp. 32-45, 2016.

[190] J. Guo, S. Ito, H. T. Nguyen et al., "Effects of prenatal exposure to triclosan on the liver transcriptome in chicken embryos," Toxicology and Applied Pharmacology, vol. 347, pp. 23-32, 2018. 
[191] X. Cao, X. Hua, X. Wang, and L. Chen, "Exposure of pregnant mice to triclosan impairs placental development and nutrient transport," Scientific Reports, vol. 7, no. 1, article 44803, 2017.

[192] X. Hua, X. Y. Cao, X. L. Wang, P. Sun, and L. Chen, "Exposure of pregnant mice to triclosan causes insulin resistance via thyroxine reduction," Toxicological Sciences, vol. 160, no. 1, pp. 150-160, 2017.

[193] W. T. Festuccia, P. G. Blanchard, T. Belchior et al., "PPAR $\gamma$ activation attenuates glucose intolerance induced by mTOR inhibition with rapamycin in rats," American Journal of Physiology Endocrinology and Metabolism, vol. 306, no. 9, pp. E1046-E1054, 2014.

[194] K. B. Paul, J. T. Thompson, S. O. Simmons, J. P. Vanden Heuvel, and K. M. Crofton, "Evidence for triclosan-induced activation of human and rodent xenobiotic nuclear receptors," Toxicology In Vitro, vol. 27, no. 7, pp. 2049-2060, 2013.

[195] D. E. Clapham, "Calcium signaling," Cell, vol. 131, no. 6, pp. 1047-1058, 2007.

[196] G. Cherednichenko, R. Zhang, R. A. Bannister et al., "Triclosan impairs excitation-contraction coupling and $\mathrm{Ca} 2+$ dynamics in striated muscle," Proceedings of the National Academy of Sciences of the United States of America, vol. 109, no. 35, pp. 14158-14163, 2012.

[197] E. B. Fritsch, R. E. Connon, I. Werner et al., "Triclosan impairs swimming behavior and alters expression of excitation-contraction coupling proteins in fathead minnow (Pimephales promelas)," Environmental Science \& Technology, vol. 47, no. 4, pp. 2008-2017, 2013.

[198] T. Kawanai, "Triclosan, an environmental pollutant from health care products, evokes charybdotoxin-sensitive hyperpolarization in rat thymocytes," Environmental Toxicology and Pharmacology, vol. 32, no. 3, pp. 417-422, 2011.

[199] V. V. Teplova, K. N. Belosludtsev, and A. G. Kruglov, "Mechanism of triclosan toxicity: mitochondrial dysfunction including complex II inhibition, superoxide release and uncoupling of oxidative phosphorylation," Toxicology Letters, vol. 275, pp. 108-117, 2017.

[200] G. McDonnell and A. D. Russell, "Antiseptics and disinfectants: activity, action, and resistance," Clinical Microbiology Reviews, vol. 12, no. 1, pp. 147-179, 1999.

[201] L. M. McMurry, M. Oethinger, and S. B. Levy, "Triclosan targets lipid synthesis," Nature, vol. 394, no. 6693, pp. 531$532,1998$.

[202] J. G. Beeson, P. A. Winstanley, G. I. McFadden, and G. V. Brown, "New agents to combat malaria," Nature Medicine, vol. 7, no. 2, pp. 149-150, 2001.

[203] H. H. Lee, J. Yun, J. Moon et al., "Crystallization and preliminary X-ray crystallographic analysis of enoyl-acyl carrier protein reductase from Helicobacter pylori," Acta Crystallographica Section D, Biological Crystallography, vol. 58, no. 6, pp. 1071-1073, 2002.

[204] J. Marcinkeviciene, W. Jiang, L. M. Kopcho, G. Locke, Y. Luo, and R. A. Copeland, "Enoyl-ACP reductase (FabI) of Haemophilus influenzae: steady-state kinetic mechanism and inhibition by triclosan and hexachlorophene," Archives of Biochemistry and Biophysics, vol. 390, no. 1, pp. 101108, 2001.

[205] R. McLeod, S. P. Muench, J. B. Rafferty et al., "Triclosan inhibits the growth of Plasmodium falciparum and Toxoplasma gondii by inhibition of apicomplexan Fab I,"
International Journal for Parasitology, vol. 31, no. 2, pp. 109-113, 2001.

[206] S. L. Parikh, G. Xiao, and P. J. Tonge, "Inhibition of InhA, the enoyl reductase from Mycobacterium tuberculosis, by triclosan and isoniazid," Biochemistry, vol. 39, no. 26, pp. 76457650, 2000.

[207] C. W. Roberts, R. McLeod, D. W. Rice, M. Ginger, M. L. Chance, and L. J. Goad, "Fatty acid and sterol metabolism: potential antimicrobial targets in apicomplexan and trypanosomatid parasitic protozoa," Molecular and Biochemical Parasitology, vol. 126, no. 2, pp. 129-142, 2003.

[208] N. Surolia and A. Surolia, “Triclosan offers protection against blood stages of malaria by inhibiting enoyl-ACP reductase of Plasmodium falciparum," Nature Medicine, vol. 7, no. 2, pp. 167-173, 2001.

[209] S. Lu and M. C. Archer, "Fatty acid synthase is a potential molecular target for the chemoprevention of breast cancer," Carcinogenesis, vol. 26, no. 1, pp. 153-157, 2005.

[210] R. Lupu and J. Menendez, "Pharmacological inhibitors of fatty acid synthase (FASN)-catalyzed endogenous fatty acid biogenesis: a new family of anti-cancer agents?," Current Pharmaceutical Biotechnology, vol. 7, no. 6, pp. 483494, 2006

[211] B. Liu, Y. Wang, K. Fillgrove, and V. Anderson, "Triclosan inhibits enoyl-reductase of type I fatty acid synthase in vitro and is cytotoxic to MCF-7 and SKBr-3 breast cancer cells," Cancer Chemotherapy and Pharmacology, vol. 49, no. 3, pp. 187-193, 2002.

[212] E. S. Pizer, C. Jackisch, F. D. Wood, G. R. Pasternack, N. E. Davidson, and F. P. Kuhajda, "Inhibition of fatty acid synthesis induces programmed cell death in human breast cancer cells," Cancer Research, vol. 56, no. 12, pp. 2745-2747, 1996.

[213] F. P. Kuhajda, K. Jenner, F. D. Wood et al., "Fatty acid synthesis: a potential selective target for antineoplastic therapy," Proceedings of the National Academy of Sciences of the United States of America, vol. 91, no. 14, pp. 6379-6383, 1994.

[214] F. P. Kuhajda, E. S. Pizer, J. N. Li, N. S. Mani, G. L. Frehywot, and C. A. Townsend, "Synthesis and antitumor activity of an inhibitor of fatty acid synthase," Proceedings of the National Academy of Sciences of the United States of America, vol. 97, no. 7, pp. 3450-3454, 2000.

[215] T. S. Ho, Y. P. Ho, W. Y. Wong, L. Chi-Ming Chiu, Y. S. Wong, and V. Eng-Choon Ooi, "Fatty acid synthase inhibitors cerulenin and C75 retard growth and induce caspase-dependent apoptosis in human melanoma A-375 cells," Biomedicine \& Pharmacotherapy, vol. 61, no. 9, pp. 578-587, 2007.

[216] M. C. Sadowski, R. H. Pouwer, J. H. Gunter, A. A. Lubik, R. J. Quinn, and C. C. Nelson, "The fatty acid synthase inhibitor triclosan: repurposing an anti-microbial agent for targeting prostate cancer," Oncotarget, vol. 5, no. 19, pp. 9362-9381, 2014.

[217] P. R. Deepa, S. Vandhana, U. Jayanthi, and S. Krishnakumar, "Therapeutic and toxicologic evaluation of anti-lipogenic agents in cancer cells compared with non-neoplastic cells," Basic \& Clinical Pharmacology \& Toxicology, vol. 110, no. 6, pp. 494-503, 2012.

[218] K. Nishi, K. Suzuki, J. Sawamoto et al., "Inhibition of fatty acid synthesis induces apoptosis of human pancreatic cancer cells," Anticancer Research, vol. 36, no. 9, pp. 46554660, 2016. 
[219] B. Schmid, J. F. Rippmann, M. Tadayyon, and B. S. Hamilton, "Inhibition of fatty acid synthase prevents preadipocyte differentiation," Biochemical and Biophysical Research Communications, vol. 328, no. 4, pp. 1073-1082, 2005.

[220] E. S. Pizer, R. J. Kurman, G. R. Pasternack, and F. P. Kuhajda, "Expression of fatty acid synthase is closely linked to proliferation and stromal decidualization in cycling endometrium," International Journal of Gynecological Pathology, vol. 16, no. 1, pp. 45-51, 1997.

[221] R. E. Wilentz, L. A. Witters, and E. S. Pizer, "Lipogenic enzymes fatty acid synthase and acetyl-coenzyme A carboxylase are coexpressed with sterol regulatory element binding protein and Ki-67 in fetal tissues," Pediatric and Developmental Pathology, vol. 3, no. 6, pp. 525-531, 2000. 


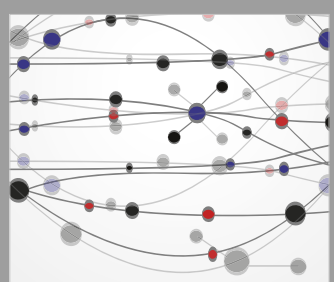

The Scientific World Journal
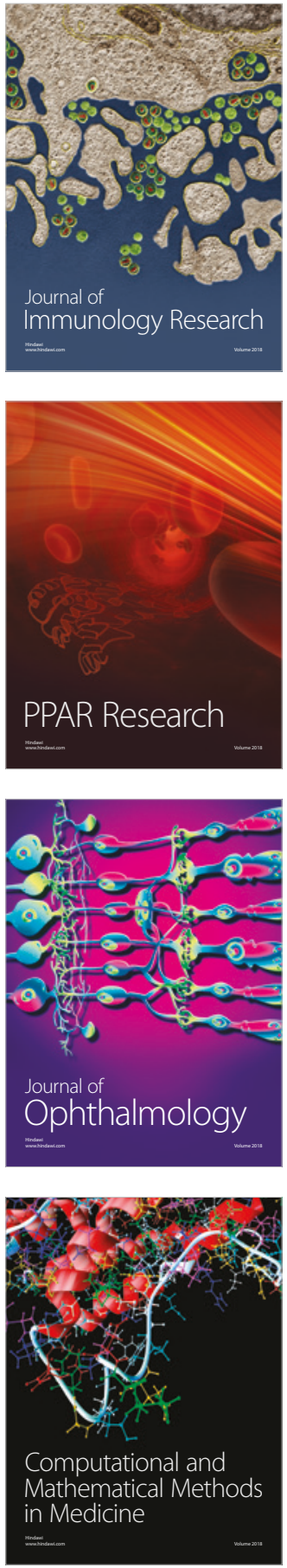

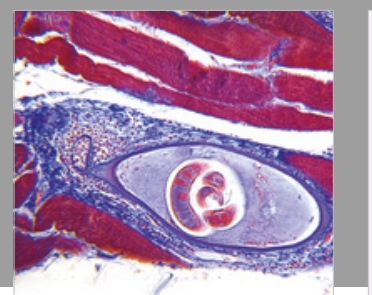

Gastroenterology Research and Practice

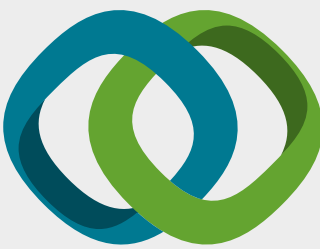

\section{Hindawi}

Submit your manuscripts at

www.hindawi.com
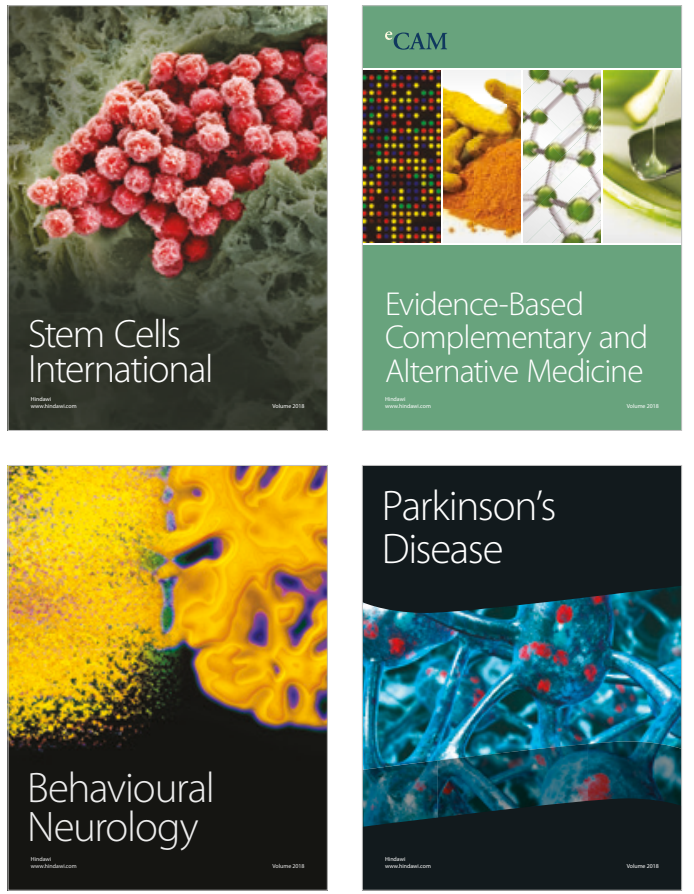

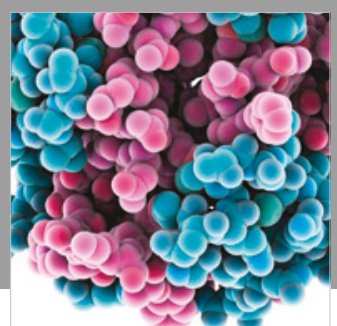

ournal of

Diabetes Research

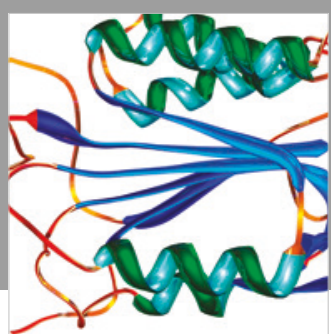

Disease Markers
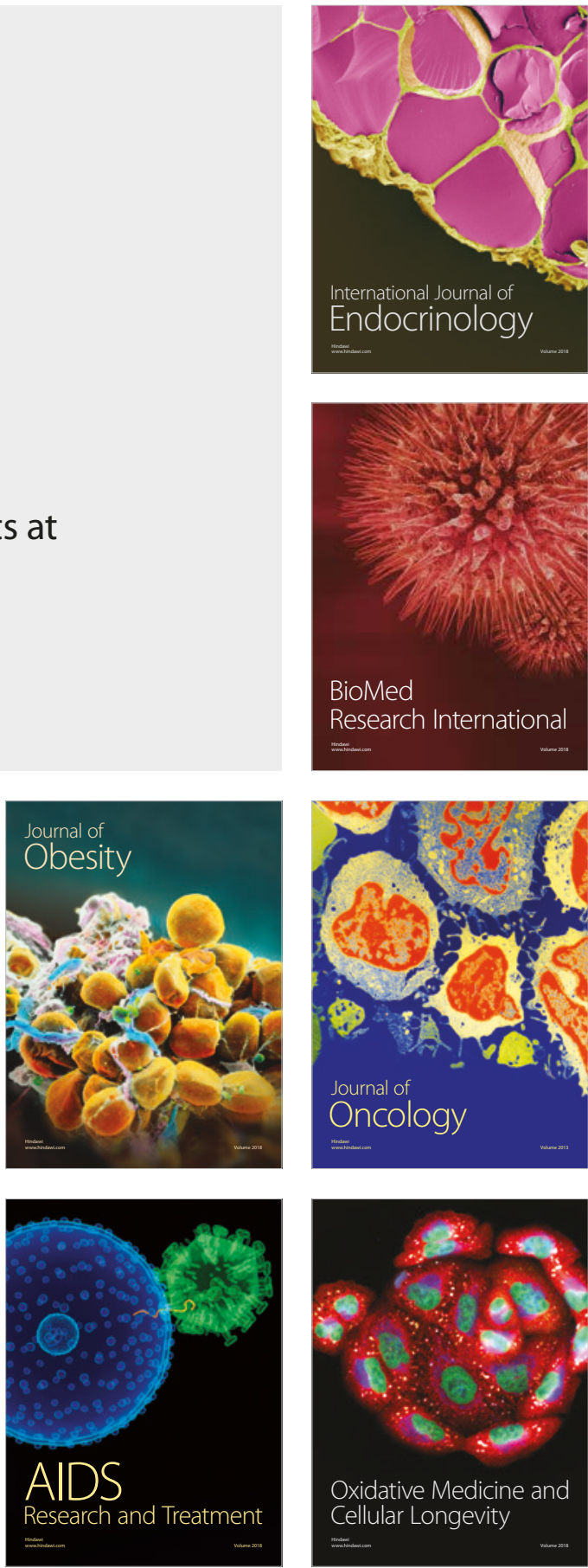